\title{
THE RELATIONSHIP BETWEEN URBAN MIDDLE SCHOOL PHYSICAL EDUCATION TEACHERS' ATTITUDES TOWARD FITNESS TESTING AND STUDENT PERFORMANCE ON FITNESS TESTS
}

\author{
by
}

Ray Noble Fredrick III

Dissertation Defense Committee:

Professor Stephen Silverman, Sponsor Professor Sharon Rose Phillips

Approved by the Committee on the Degree of Doctor of Education

\section{Date 14 February 2019}

Submitted in partial fulfillment of the requirements for the Degree of Doctor of Education in Teachers College, Columbia University 


\begin{abstract}
THE RELATIONSHIP BETWEEN URBAN MIDDLE SCHOOL PHYSICAL EDUCATION TEACHERS' ATTITUDES TOWARD FITNESS TESTING AND STUDENT PERFORMANCE ON FITNESS TESTS
\end{abstract}

\title{
Ray Noble Fredrick III
}

Quality physical education is important to adolescent health and physical wellbeing. For urban schools, contextual and environmental constraints often make schoolbased physical education challenging. A good fitness testing program has the potential to promote physical activity and fitness. Attitude theory posits that attitude influences how teachers do their work. The purpose of this study was to investigate the attitudes of urban middle school physical education teachers toward physical fitness tests and their relationship with student performance on fitness tests.

Middle school teachers $(N=124)$ were recruited from urban school districts on the east and west coasts of the United States. They completed the Physical Education Teacher Attitudes toward Fitness Tests instrument (Keating \& Silverman, 2004) whose scores have been validated and also provided demographic information. Data were analyzed using descriptive statistics for overall teacher attitude and teacher attitude subdomains and correlational statistics to examine the relationship between each component of teacher attitude (overall, affective, and cognitive) and the percentage of students in the Healthy Fitness Zone (HFZ) on various components of the FITNESSGRAM. Correlations also were examined by various teacher demographic variables and for boys and girls. Univariate and multivariate analyses were conducted to 
examine the differences in fitness tests performance variables by demographic and profession-related variables.

Teachers' overall attitudes toward fitness testing were just higher than neutral, signaling positive attitudes. Among the findings, the affective subdomain of teachers' attitude on the enjoyment of using fitness tests results was found to have a significant positive relationship with the percentage of students in the HFZ for the push-up test. Additional significant positive relationships between the percentage of students in the HFZ on the tests and various components of attitude were also found for girls.

The findings suggest that teachers' affective attitude may have a relationship with students' performance on fitness tests and that relationships may be different for boys and girls. The relationships for teachers' attitude toward enjoyment of using fitness tests results suggests teachers may use them to design activities and lessons that lead students to engage in more physical activity and thus improve their levels of fitness. 
C Copyright Ray Noble Fredrick III 2019

All Rights Reserved 


\section{ACKNOWLEDGEMENTS}

First and foremost, I'd like to thank Dr. Stephen Silverman who accepted me into the doctoral program and taught me the requisite skills to be an effective scholar. His character, knowledge, and stature in the field of education research is second to none and I am humbled to have been his student and have him as my advisor, mentor, and friend. Thank you, Steve. Also, thank you to my committee members: Drs. Phillips, DragoSeverson, and Miller. Their support and feedback will make me a better researcher and scholar. To my informal committee member Dr. Melendez, I thank for his timely feedback, support, and encouragement.

Next, I am forever indebted to my friends and colleagues. For my research seminar compadres, we pushed, encouraged, and challenged one another to be better and to finish so that we can collectively make an impact on our field. I wish all of them the best in their personal and professional endeavors. For my physical education teacher colleagues from around the country who participated in this study, thank you. Without their participation this study would not have happened.

Finally, and most importantly, I acknowledge, thank, and dedicate this dissertation to my family. My wife, Maria, for her selflessness from day one. I love and thank her for encouraging me to pursue greatness and not settle. For also being there for

our two children, Jameer and Jasmine, and helping them to realize the power of faith and family. To my parents, Ray and Patricia, my first teachers as well as teacher to so many others, I thank them for setting the example for my sister, Charryse, and I to serve and help others. Swegra and swegro, gracias!! 


\section{TABLE OF CONTENTS}

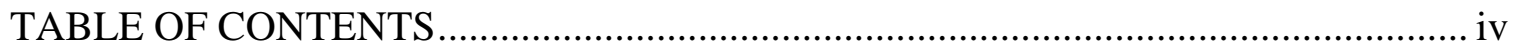

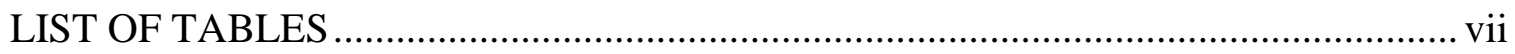

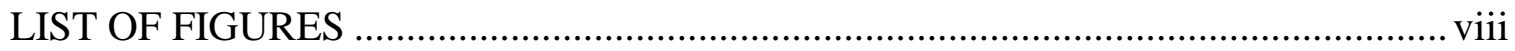

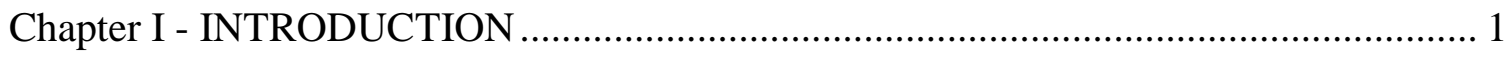

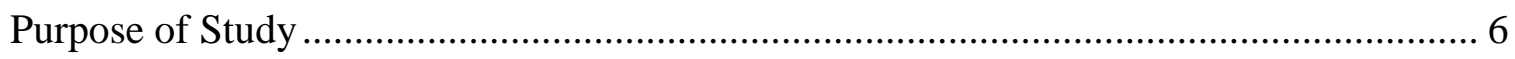

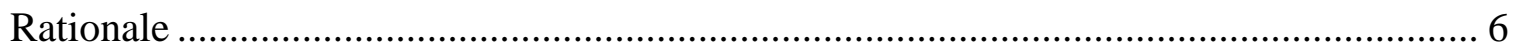

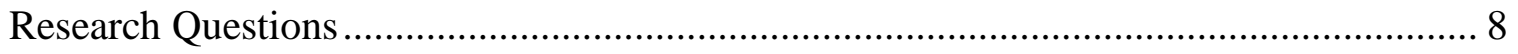

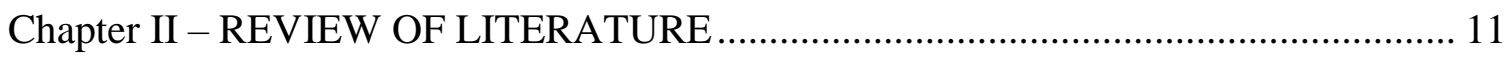

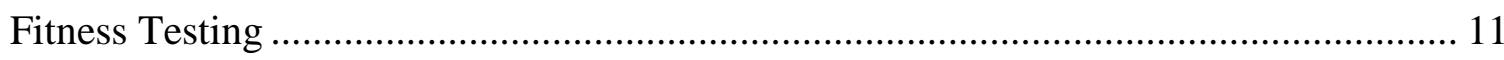

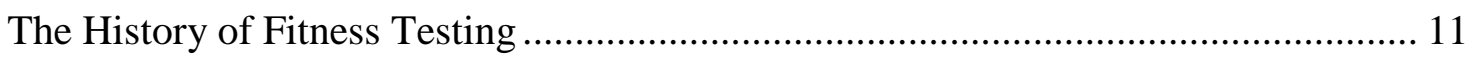

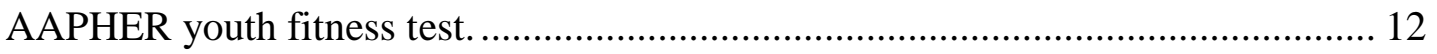

Health-related physical fitness test................................................................... 13

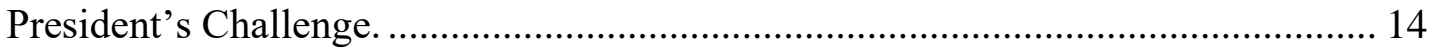

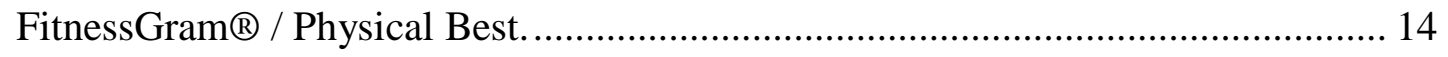

The Use of Fitness Tests in Schools................................................................... 15

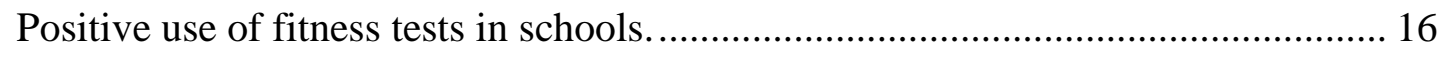

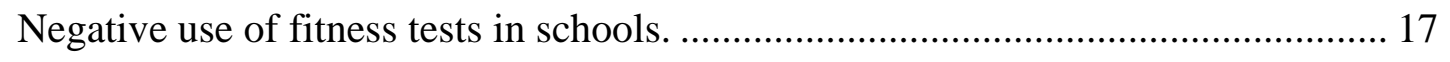

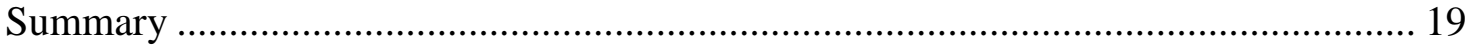

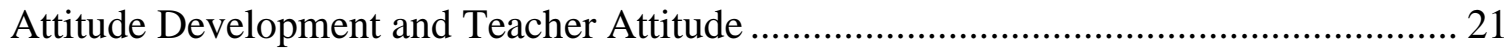

Attitude Definition and Theoretical Framework ................................................. 21

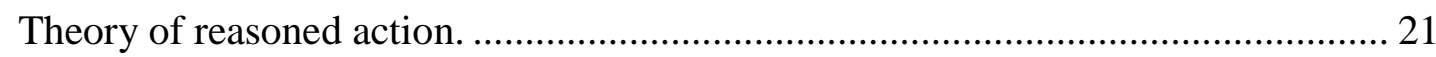

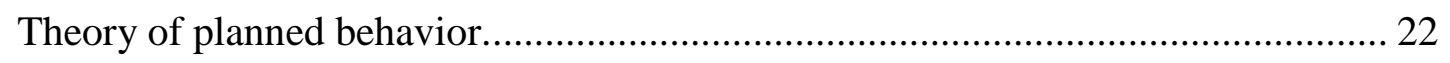

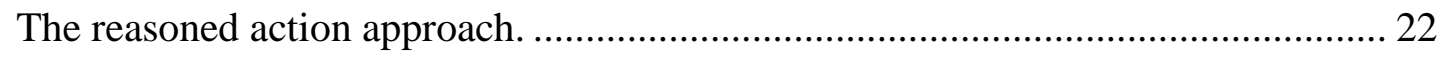

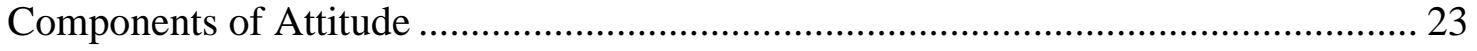

Teacher Attitude Research and Fitness Testing ..................................................... 24

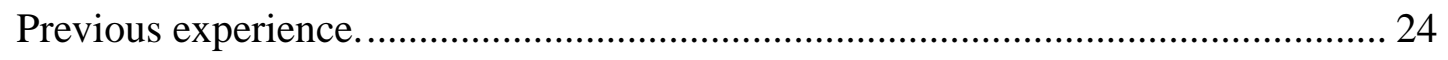

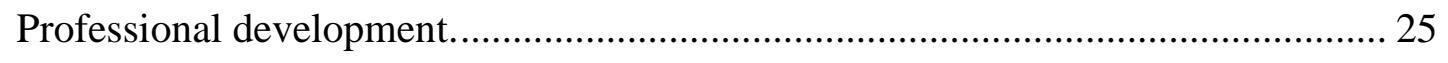

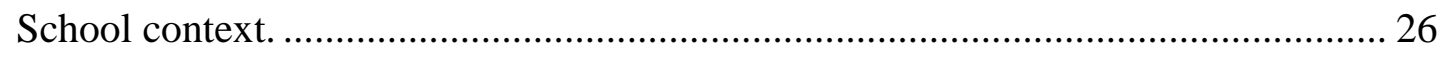




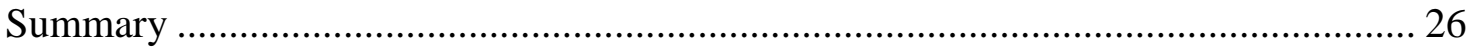

Teacher Behavior and Student Learning................................................................ 28

Teacher Attitude and Behavior Research ............................................................... 28

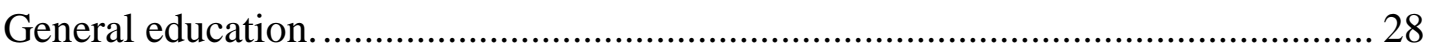

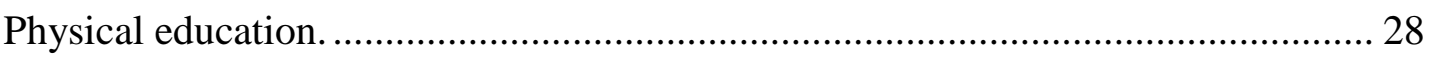

Teacher Behavior Research and Student Learning .................................................... 30

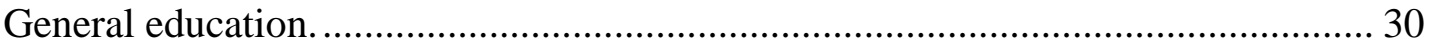

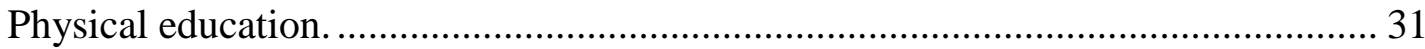

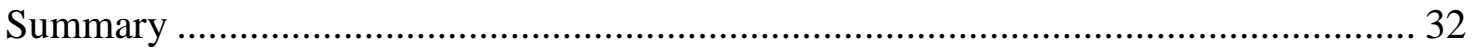

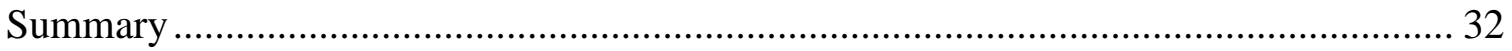

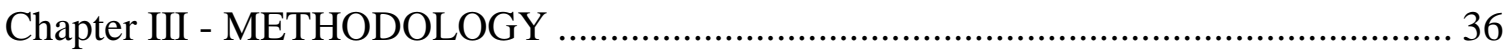

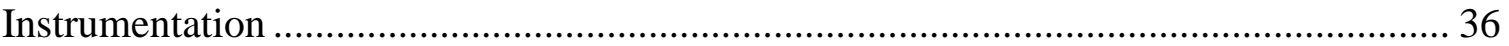

Survey Instrument for Teachers ........................................................................ 36

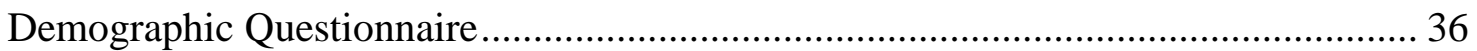

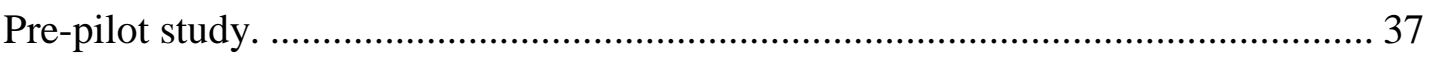

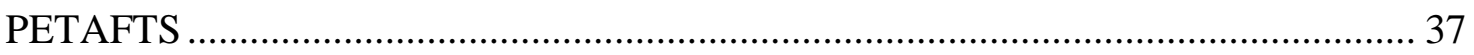

Placing Survey Online and Pilot Testing …………............................................. 39

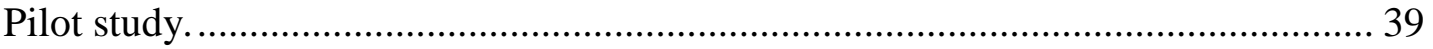

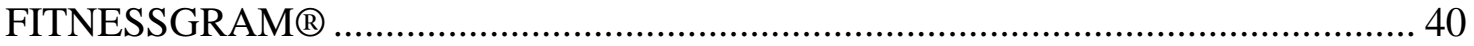

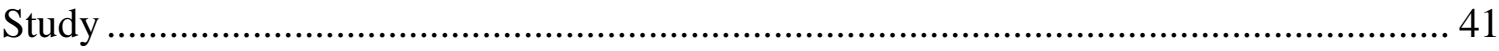

Institutional Review Board (IRB) and Protection of Human Subjects ......................... 42

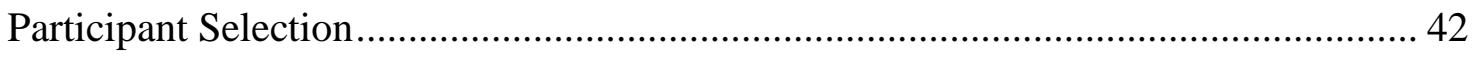

Participant Recruitment ...................................................................................... 43

Distribution of Survey Instrument to Participants ....................................................... 44

Obtaining Student FITNESSGRAM $®$ Scores .......................................................... 44

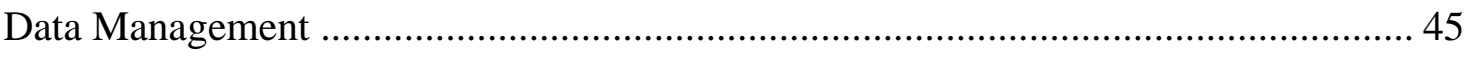

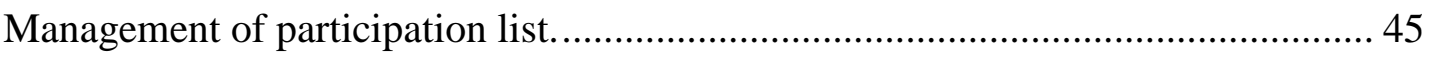

Management of FitnessGram ${ }^{\circledR}$ data........................................................................ 46

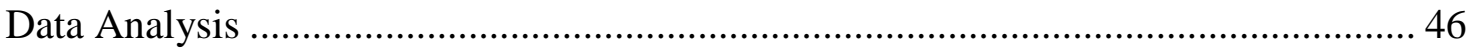

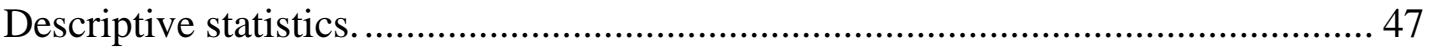

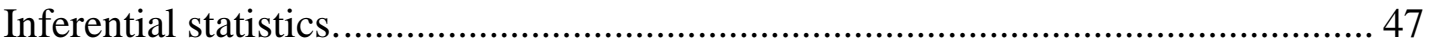

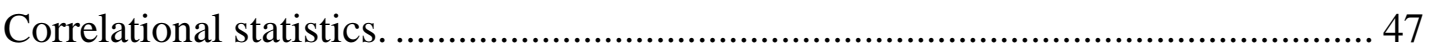




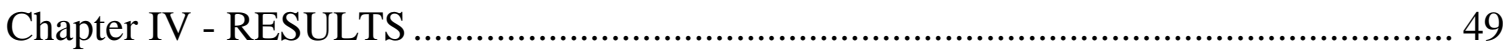

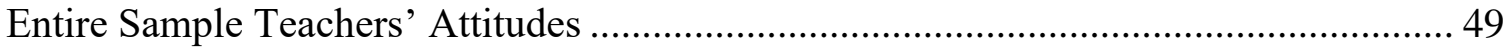

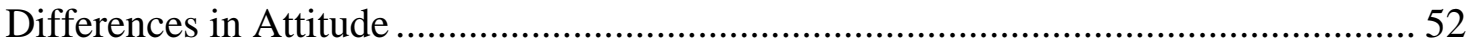

Sample with Fitness Tests Scores Descriptive Statistics ................................................. 54

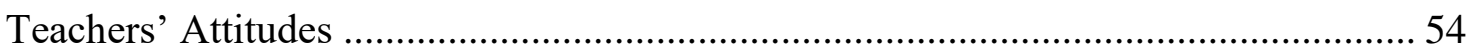

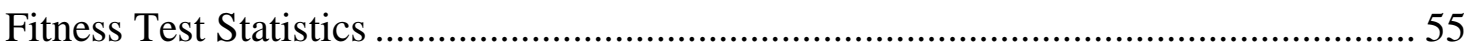

Relationships: Teachers' Attitudes and Student Performance on Fitness Tests ........... 57

Relationships: Teacher Variables and Student Performance on Fitness Tests............... 60

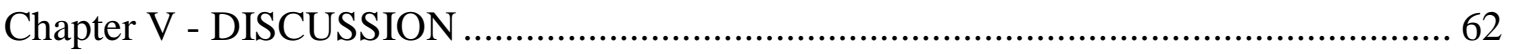

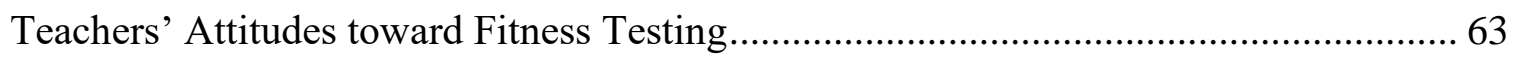

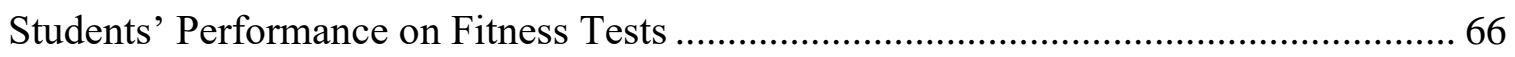

Relationships: Teachers' Attitudes and Students' Performance on Fitness Tests ........... 69

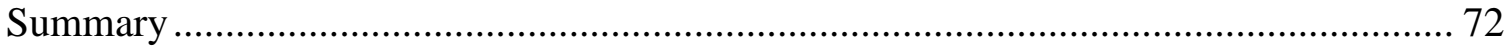

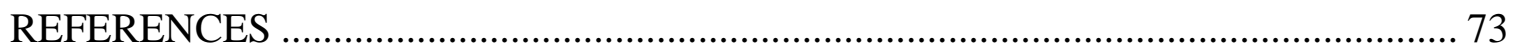

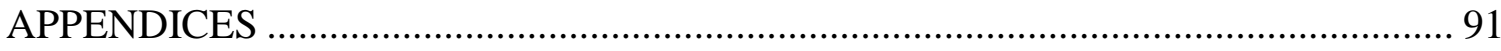

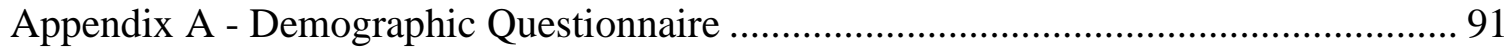

Appendix B - Physical Education Teacher Attitudes toward Fitness Tests Scale

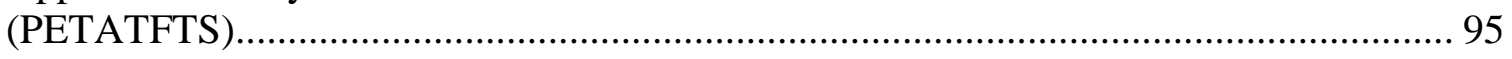

Appendix C - Pilot Study - Teacher Invitation Letter ...................................................... 97

Appendix D - Participant's Rights and Consent .............................................................. 98

Appendix E - Administrator Invitation Letter ............................................................. 100

Appendix F - Administrator Rights and Consent …………........................................ 102

Appendix G - Student Demographic and FITNESSGRAM ${ }^{\circledR}$ Data Request Sheet........ 103 


\section{LIST OF TABLES}

Table 1 Teachers' Attitudes toward Fitness Tests Descriptive Statistics.................... 50

Table 2 Teachers' Attitudes toward Fitness Tests by Gender Descriptive Statistics... 51

Table 3 Teachers' Attitudes toward Fitness Tests by Degree Descriptive Statistics ... 51

Table 4 Teachers' Attitudes Toward Fitness Testing by Age Descriptive Statistics ... 52

Table 5 Teachers' Attitudes Toward Fitness Testing Descriptive Statistics ............... 54

Table 6 Teachers' Attitudes Toward Fitness Testing by Gender .............................. 55

Table 7 Percentage of Students in HFZ on Various Components of FITNESSGRAM®

Table 8 Percentage of Students in HFZ Various Components of FITNESSGRAM® by Teacher Gender

Table 9 Relationships between Percentage of Students in HFZ and Teachers' Attitudes

Table 10 Relationship between Percentage of Female Students in HFZ and Teachers'

Attitudes

Table 11 Relationships Between Percentage of Male Students in HFZ and Teachers' Attitudes

Table 12 Relationship Between Percentage of Students in HFZ and Teachers' Age \& Teachers' Experience 


\section{LIST OF FIGURES}

Figure 1. Model of PETAFTS (Adapted from Keating et al., 2008)............................. 39 


\section{Chapter I}

\section{INTRODUCTION}

Quality physical education is an important component of the total educational program and may be a contributor to adolescent health and physical well-being (Fairclough \& Stratton, 2006; Welk, Maduro, Laurson, \& Brown, 2011). The goal of physical education is to develop physically literate individuals who have the knowledge, skills, and confidence to enjoy a lifetime of healthful physical activity (SHAPE, 2014). Current national standards for physical education (SHAPE, 2014) emphasize the central

place of adolescent health and fitness (Standard 3). Reflecting the importance of physical and fitness education, all 50 states have learning standards centered on health-related fitness (Centeio \& Keating, 2011). Further, of the 26 states that require some form of student assessment in physical education, 54\% (14) require assessment of physical fitness (NASPE, 2012). An educational component of fitness that has the potential to promote physical activity and improve health-related fitness is fitness testing (Keating \& Silverman, 2004b; Pate, 1991; Silverman, Keating, \& Phillips, 2008). Despite variability in the types of fitness tests used in schools, fitness testing has been reported as the most common form of assessment used in physical education (Ferguson, Keating, Bridges, Guan, \& Chen, 2007).

While the use of fitness testing in American schools has a long history (Brace, 1947; Corbin \& Pangrazi, 1992; Pate, 1989; Landwer, 2009; McCloy \& Young, 1954), 
recent research on the increasing prevalence of childhood obesity (Ogden, Carroll, Kit, \& Flegal, 2014; USDHHS, 2012), health benefits of physical activity and fitness (USDHHS, 2008), and the link between physical activity and academic achievement (CDC, 2010; Hillman et al., 2012; Howie \& Pate, 2012) has led to an increased emphasis on fitness assessment. The literature on fitness testing highlights positive and negative uses of fitness tests in schools (Ernst, Corbin, Beighle, \& Pangrazi, 2006; Keating, 2003; Keating \& Silverman, 2004b; McKenzie, 2003; Silverman et al., 2008; Wiersma \& Sherman, 2008). For example, following the passage of the No Child Left Behind (NCLB) Act of 2001, many schools and physical education programs began using fitness testing as the major form of accountability with instruction focused on increasing test scores (IOM, 2013; Silverman et al., 2008). This negative use of fitness testing as an accountability measure is not educationally sound and may contribute to the negative attitudes and behaviors regarding fitness testing among teachers and students.

When used appropriately, fitness tests have the capability not only to measure physical fitness but also to motivate, teach, and encourage individuals (including adolescent youth) to pursue a healthy and active lifestyle (Wiersma \& Sherman, 2008; Silverman et al., 2008). As a teaching tool, fitness tests can be positively used by teachers to assess their fitness instruction, assess their students' learning, and analyze their fitness education program (Corbin, 1981; Silverman et al., 2008). These positive uses of fitness tests contribute to the total physical education program and the development of physically literate individuals who have the knowledge, skills, and confidence to pursue a physically active lifestyle. 
Research on fitness testing, to date, has focused primarily on fitness test validity and reliability (Baumgartner \& Gaunt, 2005; Lubans et al., 2011; Pate, Burgess, Woods, Ross, \& Baumgartner, 1993; Safrit, 1990; Sherman \& Barfield, 2006) and on fitness tests scores in predicting physical activity across the lifespan of an individual (IOM, 2012; Ortega, Ruiz, Castillo, \& Sjostrom, 2008; Ortega et al., 2011). The findings from these studies, for the most part, indicate that fitness test scores are a valid and reliable measurement and that a positive correlation between fitness performance and physical activity engagement exists for both children and adults. Recently, a few studies (Mercier \& Silverman, 2014; Wittberg, Cottrell, Davis, \& Northrup, 2010; Zhu \& Chen, 2015; Zhu, Chen, \& Parrott, 2014) have examined fitness testing in schools to understand their place and significance in education, specifically in physical education and with regard to physical activity outcomes. Understanding the potential role of teachers' attitudes toward fitness tests as a factor influencing student performance on fitness tests will provide new and distinct evidence about fitness testing in schools.

Studies on teacher characteristics, attitudes, and behaviors associated with student learning (Bai \& Ertmer, 2008; Brickhouse, 1990; Crawley, 1990; Eisner \& Vallance, 1974; Ennis, 1992; Lumpe, Czerniak, Haney, \& Beltyukova, 2012; Lumpe, Haney, \& Czerniak, 1998; Mansour, 2009; McNeil, 1990; Pajares, 1992; Kulinna \& Silverman, 2000) have produced encouraging results. Additionally, studies across multiple education domains have found teacher effects on student learning (Doyle, 1978, 1979, 1983; Good, Biddle, \& Brophy, 1975; McConnell, 1977; Murnane \& Phillips, 1981; Wenglinsky, 2002, 2003) to be positive, cumulative, and long-lasting. Specifically, 
learning climate, skill progression, task presentation, accountability, and appropriate practice opportunities are identified as key factors in student learning that a teacher contributes to. From this evidence, the premise that teachers' attitudes contribute to student learning and performance can be put forth and investigated.

A person's attitude toward an object of interest or behavior is the first determinant of his/her behavioral intention (Ajzen \& Fishbein, 1980). Attitude is defined as the favorable or unfavorable feeling that an individual has toward an object or behavior, which is determined by one's personal beliefs about the outcomes associated with the object of interest or behavior and the positive or negative evaluation of these outcomes. Once a set of beliefs is formed and is accessible in memory, it provides the cognitive foundation from which attitudes are assumed to follow automatically in a reasonable and consistent fashion (Ajzen, 2012). Informed by the theories of reasoned action (TRA) and planned behavior (TPB), this research study focuses on urban physical education teachers' attitudes toward fitness tests and their relationship to student performance on fitness tests.

Physical education teachers, the primary administrators of fitness testing, are moved to evaluate and assess student performance on fitness tests in ways that align with a predetermined set of beliefs regarding fitness tests. These beliefs have been formed through personal and professional experiences (Calderhead \& Robson, 1991; Goodman, 1988; Hopple \& Graham, 1995; Keating, Silverman, \& Kulinna, 2002), professional preparation and development (Conkle, 1997; McKenzie \& Sallis, 1996; Whitehead, 1989), and situational contexts (Ferguson et al., 2007; Keating, 2003; Kulinna \& 
Silverman, 2000). It is these beliefs that produce a teacher's overall attitude toward fitness tests. Favorable attitudes toward fitness tests have been found to be associated with positive practices with fitness tests (Mercier et al., 2016), whereas unfavorable attitudes may contribute to negative practices with fitness tests (Keating \& Silverman, 2004b). In both general and physical education, teachers' attitudes have been found to influence curriculum content priorities (Ennis, 1992, 1994a; Placek \& Dodds, 1988) and teacher behavior (Bai \& Ertmer, 2008; Brickhouse, 1990; Lumpe et al., 1998; Lumpe et al., 2012).

School-based physical education (SBPE) classes are important for urban adolescents in achieving the recommended 60 minutes of daily moderate-to-vigorous physical activity (Gordon-Larsen, McMurray, \& Popkin, 2000; IOM, 2012; Martin \& McCaughtry, 2008; NASPE, 2012; Racette et al., 2015; USDHHS, 2008). Scholars in physical education pedagogy and in measurement and assessment (Silverman et al., 2008) have suggested that fitness instruction, as part of a comprehensive physical education program, could focus on using fitness tests to help students develop fitness and physical activity plans that can be performed in areas with limited resources (e.g., facilities, equipment). Urban schools, particularly urban physical education teachers, are oftentimes challenged by limited facilities, equipment, instructional time, and professional development (Chen, 1998; Cothran \& Ennis, 1997; Ennis 1995, 1996b, 1998; Ennis et al., 1997; McCaughtry, Barnard, Martin, Shen, \& Hodges-Kulinna, 2006). As teachers in urban schools have different backgrounds and experiences with fitness tests, understanding their attitudes toward fitness tests in relation to their students' 
performance on fitness tests may provide valuable insight into their use in teaching and learning in physical education.

\section{Purpose of Study}

The purpose of this study is to investigate the attitudes of urban middle school physical education teachers toward physical fitness tests. A second purpose of this this study is to examine the relationship between urban middle school teachers' attitudes toward fitness testing and student performance on fitness tests.

\section{Rationale}

Research into teachers' attitudes, practices, knowledge, and student outcomes with respect to fitness testing will provide practical and theoretical implications for researchers, educators and policymakers. Attitudes held by urban middle school physical educators may suggest that they influence student performance and ultimately contribute to physical activity levels among adolescent youth. By examining the relationship between urban middle school teachers' attitude toward fitness testing and student performance on fitness tests, it may be possible, from a practical standpoint, to develop interventions to influence urban middle school teachers' attitude toward fitness testing. A positive shift in attitudes, ultimately, could have an important influence on both how 
fitness tests are used in schools and in advancing healthy and active lifestyles among the individuals that use them.

Theoretically, this study will examine and add to the TRA and TPB by investigating teachers' attitudes in urban middle school physical education settings. Currently, the research on physical education teachers' attitudes toward fitness tests is limited. Physical educators in urban environments are often challenged with limited access to space and equipment, suggesting that internal and external barriers may be the strongest predictor of teacher behavior. This study could provide information to either affirm this suggestion or present an alternative one that suggests teachers' attitudes may also be a strong predictor in teacher behavior, through its relationship with student performance.

This study will add to what we already know about teachers' attitudes toward fitness tests as well as fill an existing gap that exists between teachers' attitudes toward fitness tests and student outcomes. The evidence that a decline in participation coincides with middle and high school (Biddle, Gorely, \& Stensel, 2004; Fairclough \& Stratton, 2005) and that physical inactivity is disproportionately prevalent among school-aged urban minority youth (Basch, 2011) demands further research into the contribution that urban middle school teachers make to physical activity participation. Experts and scholars agree that quality physical education is important to adolescent health and physical well-being and that fitness activities result in more physical activity (IOM, 2013). Moreover, they believe fitness tests have the potential to promote physical activity and help adolescents learn about fitness. This study will provide useful 
information to assist researchers and educators alike in improving how fitness tests are used in teaching and learning in physical education.

\section{Research Questions}

This research study will look to answer the following research questions:

What are urban middle school physical education teachers' attitudes toward physical fitness tests?

1a. Are there differences in urban middle school physical education teachers' attitudes toward fitness tests by gender?

1b. Are there differences in urban middle school physical education teachers' attitudes toward fitness tests by teaching experience?

1c. Are there differences in urban middle school physical education teachers' attitudes toward fitness tests by teacher age?

What is the relationship between urban middle school physical education teachers' attitudes toward physical fitness testing and students' performance on physical fitness tests?

2a. Are there differences in urban middle school physical education teachers' attitudes toward fitness testing and students' performance on physical fitness tests by student gender? 
2b. Are there differences in urban middle school physical education teachers' attitudes toward fitness testing and students' performance on physical fitness tests by teaching experience?

2c. Are there differences in urban middle school physical education teachers' attitudes toward fitness testing and students' performance on physical fitness tests by tests by teacher age?

What is the relationship between the cognitive component of urban middle school physical education teachers' attitude toward physical fitness testing and students' performance on physical fitness tests?

3a. Are there differences in the relationship between the cognitive component of urban middle school physical education teachers' attitudes toward fitness testing and students' performance on physical fitness tests by student gender?

3b. Are there differences in the relationship between the cognitive component of urban middle school physical education teachers' attitudes toward fitness testing and students' performance on physical fitness tests by teaching experience?

3c. Are there differences in the relationship between the cognitive component of urban middle school physical education teachers' attitudes toward fitness testing and students' performance on physical fitness tests by teacher age?

What is the relationship between the affective component of teachers' attitude toward physical fitness testing and students' performance on physical fitness tests? 
4a. Are there differences in the relationship between the affective component of urban middle school physical education teachers' attitudes toward fitness testing and students' performance on physical fitness tests by student gender?

4b. Are there differences in the relationship between the affective component of urban middle school physical education teachers' attitudes toward fitness testing and students' performance on physical fitness tests by teaching experience?

4c. Are there differences in the relationship between the affective component of urban middle school physical education teachers' attitudes toward fitness testing and students' performance on physical fitness tests by teacher age? 


\section{Chapter II}

\section{REVIEW OF LITERATURE}

For the purposes of this study, the review of literature will be divided into three sections and focus on attitude, teaching, and learning. First, the literature on fitness testing will be reviewed to provide an understanding of fitness testing and its role in the learning process as well as its function in the continuous improvement of curriculum and instruction. Second, a theoretical overview of attitude and its components will be presented. Finally, the research on teacher attitude, teacher behavior, and student learning will be reviewed.

\section{Fitness Testing}

\section{The History of Fitness Testing}

The use of fitness testing in American schools has a long history (Brace, 1947; Landwer, 2009; McCloy \& Young, 1954). It was not until the 1950's, however, that youth fitness became a national issue and prompted the development of a national fitness test. In 1954, a seminal study by Kraus and Hirschland (1954) reported that $57.9 \%$ of American youth failed a minimum muscular fitness test, a bleak percentage in comparison with the $8.7 \%$ of European youth who failed the same fitness test. The results from this comparative study caught the attention of then-President Eisenhower 
and ushered in the President's Council on Youth Fitness (PCYF), which created the first national fitness testing program in collaboration with the American Alliance for Health, Physical Education, and Recreation (AAHPER) (AAHPER, 1958, 1965; American Alliance for Health, Physical Education, Recreation, and Dance [AAHPERD], 1976). Throughout the 1960s and 1970s, the original national youth fitness test would undergo several revisions.

AAPHER youth fitness test. The first edition of the AAHPER Youth Fitness Test (YFT) was published in 1958 as a result of the aforementioned Kraus and Hirschland (1954) report and the subsequent meetings held by various organizations, to include the PCYF and AAHPER. For two decades, the AAHPER YFT would serve as the only nationally available youth fitness test (Morrow, Zhu, Franks, Meredith, \& Spain, 2009; Pate, Welk, \& McIver, 2013). The AAHPER YFT battery was norm-referenced and included measures of strength, muscular endurance, and both health and skill-related components of fitness (Morrow et al., 2009). Further, the AAHPER YFT standards and normative percentiles were based on scores obtained from a nationwide sample of 8,500 school children in the $5^{\text {th }}$ through $12^{\text {th }}$ grades (AAHPER, 1958). Information gathered from the AAHPER YFT was used to evaluate specific aspects of physical status and develop programs to improve the physical fitness of Americans, with a particular emphasis on the nation's youth.

The first edition of the AAHPER YFT consisted of seven items until its modification and update in 1965. The second edition of the AAHPER YFT replaced the modified pull-up with the flexed arm hang for girls in an effort to improve score 
reliability (AAHPER, 1965). In addition, the second edition of the test was adopted by the President's Council on Physical Fitness (PCPF), which established the Presidential Physical Fitness Award Program to acknowledge individual performance on the test (Freedson, Cureton, \& Heath, 2000; Keating, 2003). A third and final edition of the AAHPER YFT was published in 1976 (AAHPERD, 1976). This edition of the YFT consisted of six items, with the softball throw being eliminated completely to move the test away from athletic skills and more toward functional health and fitness (Franks, Morrow, \& Plowman, 1988; Keating, 2003). Beginning in the 1980s and continuing into the 1990s, as a result of this lack of consensus over whether tests should focus on motor skills or the health-related components of fitness, a number of different fitness tests emerged and competed on a national scale to prove their position as the primary fitness test for the nation's school children.

Health-related physical fitness test. In response to the growing controversy over the motor fitness approach to fitness testing, AAHPERD published the HealthRelated Physical Fitness Test (HRPFT) in 1981 (AAHPERD, 1980). The HRPFT battery included items measuring cardiorespiratory fitness, musculoskeletal fitness, and body composition (AAHPERD, 1984; Franks et al., 1988; Morrow et al., 2009; Safrit \& Wood, 1986, 1987). The HRPFT, while psychometrically valid, was not well received by teachers and administrators (Morrow et al., 2009), which would play a key role in the ongoing advancement of fitness test development among AAHPERD, the President's Council on Physical Fitness and Sports (PCPFS), and other organizations, to include the Cooper Institute. 
With meager support for the HRPFT, AAHPERD tried to rely on the Youth Fitness Test and its relationship with the PCPFS to create one unified national test incorporating items from both the HRPFT and the Youth Fitness Test. In the end, the two organizations were not able to agree and unify and thus went their separate ways, with the PCPFS remaining focused on motor skill and AAHPERD continuing to develop health-related fitness tests (Keating, 2003; Morrow et al., 2009).

President's Challenge. Published in 1987, the President's Challenge Fitness Test was based primarily on the 1985 AAHPERD YFT (Morrow et al., 2009) and differentiated itself from its competitors by promoting its long-standing awards recognition program. The President's Challenge continued to measure cardiorespiratory endurance, muscular strength, and flexibility. Also, it continued to serve as a normreferenced test rather than a criterion-referenced test, which had been suggested during meetings with AAHPERD in their ongoing negotiations to create a unified national fitness test. The President's Challenge Program remained steadfast in not measuring the body composition component of health-related fitness (Morrow et al., 2009) but rather focusing on performance-based measures.

FitnessGram ${ }^{\circledR}$ / Physical Best. FitnessGram ${ }^{\circledR}$ was developed in 1982 by the Cooper Institute for Aerobics Research (CIAR) to test and measure both skill and healthrelated fitness utilizing a computer program (Morrow et al., 2009; Plowman et al., 2006). Originally formed as a combination of the AAHPERD HRPFT and the PCPFS YFT, FitnessGram ${ }^{\circledR}$ developed into an independent test based on the health-related components of fitness. In 1993, FitnessGram® and AAHPERD formed a strategic 
partnership that merged AAHPERD's Physical Best, its health-related fitness test and education program, with FitnessGram ${ }^{\circledR}$. The partnership established FitnessGram ${ }^{\circledR}$ as the health-related physical fitness test and reporting program, while Physical Best became the education program (Keating, 2003; Plowman et al., 2006).

Today, the FitnessGram ${ }^{\circledR}$ test battery measures aerobic capacity, body composition, muscular strength, muscular endurance and flexibility. FitnessGram ${ }^{\circledR}$ is a criterion-referenced test, the first youth fitness test utilizing criterion referenced standards (Plowman et al., 2006). In addition, FitnessGram® created and uses "Healthy Fitness Zones" to help students, parents and teachers to evaluate, track and plan fitness progress. FitnessGram ${ }^{\circledR}$ is the official national fitness test of the Presidential Youth Fitness Program (PYFP) and has a goal to reach 90\% of the nation's schools by the year 2020 (Corbin et al., 2014).

\section{The Use of Fitness Tests in Schools}

The use of fitness testing in American schools has a long history (Brace, 1947; Corbin \& Pangrazi, 1992; Pate, 1989; Landwer, 2009; McCloy \& Young, 1954). While many uses of fitness testing have changed over the years, the primary use of fitness testing was, and remains, to provide a measure of physical fitness for both boys and girls in American schools (AAHPERD, 1976; Safrit \& Wood, 1986). How this measure of physical fitness is interpreted, communicated and recognized, among other actions, are additional uses of fitness tests that, ultimately, divide fitness test practices within American schools into two distinct categories: the positive and negative use of fitness 
tests. The primary goal of physical education is to develop physically literate individuals who have the knowledge, skills and confidence to enjoy a lifetime of healthful physical activity (Society of Health and Physical Educators, 2014) and fitness testing in schools can and should be a part of accomplishing this goal (Ernst et al., 2006; Mercier \& Silverman, 2014; NASPE, 2004; Silverman et al., 2008).

Positive use of fitness tests in schools. Fitness testing in schools is an important piece in effectively assessing fitness education (Silverman et al., 2008). In education, assessment is vitally important to the learning process as well as necessary for the continuous improvement of curriculum and instruction (Huba \& Freed, 2000). In order to determine whether students have mastered what they were taught and whether the information in the curriculum is aligned to the objectives it aims to accomplish, assessment must be present. So, fitness testing is an assessment tool that can, is, and should be used by teachers in the physical education classroom to assess student learning when fitness activities are taught (Silverman et al., 2008) in addition to assessing whether or not teachers are using effective instructional and pedagogical techniques to properly transfer knowledge from the curriculum to the student (Ernst et al., 2006; Silverman et. al., 2008).

An additional use of fitness testing in schools centers on teaching students how to self-assess their own fitness performance (Keating, 2003; Silverman et al., 2008; Wiersma \& Sherman, 2008) in order to promote lifelong physical activity (Corbin, 2002; Silverman et al., 2008). Several studies have shown that students have little or no understanding of the purpose of fitness tests (Hopple \& Graham, 1995; Keating \& 
Silverman, 2009; Placek et al., 2001). Helping students to understand the purpose of fitness tests and how to use fitness tests to achieve health-related goals would help in achieving the positive use of fitness tests by many physical educators. After all, the primary goal of physical education is to develop physically literate individuals who have the knowledge, skills and confidence to enjoy a lifetime of healthful physical activity (SHAPE, 2014).

Various motivating factors exist in physical education and help tremendously in the process of developing confident individuals that have positive attitudes toward physical activity. The use of fitness testing as a motivating tool is valuable in the educational process as it has great potential to impact not only favorable attitudes towards fitness testing but also various types of physical activity. When students understand how and are able to individually track fitness results over time, within a sound fitness education program, they are often motivated to improve and change their performance levels (Wiersma \& Sherman, 2008). This process of individual evaluation and accountability allows students to realize that they can be their own change agent through hard work and persistence. By positively influencing student attitudes toward fitness testing and physical activity, students are more likely to participate in physical activity and thus lead physically active lifestyles (Martin, Oliver, \& McCaughtry, 2007; Solmon, 2003; Trost, Saunders, \& Ward, 2002).

Negative use of fitness tests in schools. In the highly charged era of high-stakes testing and accountability in education, fitness testing in schools faces the difficult task of not being used as an accountability procedure in evaluating students, teachers or 
programs in physical education (Ernst et al., 2006; Keating, 2003; McKenzie, 2003;

Silverman et al., 2008; Wiersma \& Sherman, 2008). Quality physical education programs develop not only health and skill-related fitness, but also the additional attributes of physical competence and cognitive understanding about physical activity so that students can adopt healthy and physically active lifestyles (NASPE, 2003). Fitness test scores alone should not be used to evaluate the physical education student, teacher or program because performance batteries are not designed to cover the full range of objectives that make up the physical education curriculum (Ernst et al., 2006). Additionally, heredity plays a significant role in the level of performance on fitness tests (McKenzie, 2003) and some students may excel but not for a lack of effort and practice. Choosing to use one factor in determining the grade for a student, teacher or program represents an unfavorable and negative use of fitness testing in schools.

The administration of fitness testing in schools is often an arduous task due to limitations in resources, staffing and allocated time, thus making student performance a public event rather than an individual assessment of performance (Ernst et al., 2006; Wiersma \& Sherman, 2008). By not ensuring the privacy and confidentiality of individual student data through proper procedures, administrators of fitness tests allow a culture to build that quite often lead to students feeling embarrassed and ridiculed, feelings that create unfavorable attitudes toward fitness testing and ultimately physical activity. Appropriate administration and protocols regarding student confidentiality must be practiced in implementing fitness tests to ensure the success of fitness testing in reaching its intended objectives (Ernst et al., 2006). The recommended and positive use 
of fitness testing, to include using fitness tests as both a self-assessment and motivational tool, are important to remember in effectively guarding against the detrimental effects of fitness testing when used in inappropriate and negative ways.

\section{Summary}

Fitness testing has been an important component in American schools and physical education for over a half-century (Brace, 1947; Kraus \& Hirschland, 1954; Landwer, 2009; McCloy \& Young, 1954). The subject of fitness testing was brought to the national agenda in the 1950's when then-President Eisenhower ushered in the President's Council on Youth Fitness (PCYF) to create the first national fitness testing program in collaboration with the American Alliance for Health, Physical Education, and Recreation (AAHPER) (AAHPER, 1958, 1965; American Alliance for Health, Physical Education, Recreation, and Dance [AAHPERD], 1976) as the result of a seminal study (Kraus \& Hirschland, 1954) that showed the American youth to be unfit in comparison with their European counterparts. A sound and able body was viewed then, as it still is today, as important to achievement and performance in the lives of the nation's citizens.

The development of youth fitness testing started with the AAHPER YFT. Its primary use was as an information gathering tool to evaluate specific aspects of physical status in order to develop programs that would improve the physical fitness of Americans, with a particular emphasis on the nation's youth. Over time, fitness testing underwent many revisions in order to develop a comprehensive measurement of youth fitness that included items from health-related and skill-related fitness in addition to 
serving as an educational tool to improve teaching and learning. Today, the official national youth fitness test, FitnessGram ${ }^{\circledR}$, is a criterion-referenced test that measures aerobic capacity, body composition, muscular strength, muscular endurance and flexibility as well as helps students, parents and teachers to evaluate, track and plan fitness progress (Plowman et al., 2006).

While the function of fitness testing has created differences among individuals, groups and organizations with an interest in the field of physical education, it is well supported that fitness testing in schools can and should be a part of accomplishing physical education's primary goal (Ernst et al., 2006; Mercier \& Silverman, 2014; NASPE, 2004; Silverman et al., 2008), which is to develop physically literate individuals who have the knowledge, skills and confidence to enjoy a lifetime of healthful physical activity (SHAPE, 2014). When the appropriate administration and protocols regarding fitness testing are practiced, students learn the purpose of fitness tests and how to use fitness tests to achieve health-related goals, how to self-assess their own fitness performance (Keating, 2003; Silverman et al., 2008; Wiersma \& Sherman, 2008), and how to use fitness tests as both a self-assessment and motivational tool. Ultimately, these positive benefits of physical fitness testing contribute to the goal of developing physically literate individuals who have the knowledge, skills and confidence to enjoy a lifetime of healthful physical activity (SHAPE, 2014). 


\section{Attitude Development and Teacher Attitude}

\section{Attitude Definition and Theoretical Framework}

A person's attitude is important to his or her behavior. Attitude is defined as an individual's positive or negative belief toward an object and the evaluation of a behavior associated with this belief (Ajzen, 1991; Fishbein \& Ajzen, 1975). According to Rokeach (1968), beliefs may be descriptive, evaluative, or prescriptive, with the presence of all three elements usually present in an individual's beliefs. An individual's belief about an object is very important in determining their disposition (Brown \& Cooney, 1982), evaluation and behavioral response toward that object (Bandura, 1986; Rikard \& Banville, 2006). A positive attitude toward an object generally results in a positive association with and positive behavior toward the object (Ajzen, 1991). Conversely, a negative attitude toward an object usually results in a negative behavior toward the object (Silverman \& Subramaniam, 1999).

Theory of reasoned action. Ajzen \& Fishbein's (1980) theory of reasoned action (TRA) advances the idea that behavioral intention is a function of an individual's attitude toward a behavior and the attitude of others toward the same behavior. Attitude, the positive or negative feeling that an individual has toward a behavior, is determined by one's personal beliefs about the consequences of engaging in a behavior. Normative beliefs have to do with the social environment and climate surrounding a behavior and whether or not there is social pressure to perform or not perform a certain behavior. Each 
of these two conceptually independent constructs of behavior influence behavior by combining with the other to form intention.

Theory of planned behavior. The Theory of Planed Behavior (TPB) is an extension of the TRA. The TPB builds on the TRA by adding an additional construct to the existing attitude and subjective norm constructs that form intention. In the TPB, one's behavior is determined by a combination of one's behavioral beliefs, normative beliefs and control beliefs (Ajzen, 1989). Control beliefs have to do with the level of confidence an individual has in performing a behavior free of barriers and obstacles. The construct of attitude, subjective norm and perceived behavioral control form one's intention to engage in a behavior. The TPB asserts that intention is the most important determinant of behavior.

The reasoned action approach. Extending the TPB, Ajzen \& Fishbein (2010) produced the reasoned action approach by adding an additional construct, actual behavior, and modifying the subjective norm construct, by renaming it perceived norm, to more accurately reflect that perception is more important than fixed norms toward the attitude object. In addition to adding and modifying a construct, Ajzen \& Fishbein (2010) include beliefs as a fourth level, placed in front of the previous first level from the TRA and TPB, to emphasize the influence that behavioral, normative, and control beliefs have on attitude, perceived norm, and perceived behavioral control. 


\section{Components of Attitude}

Attitude has been studied extensively in different fields by individuals who wish to understand how its construction explains human behavior and performance (McGuire, 1969; Ajzen, 2001). While some researchers have chosen to apply a multi-component model of attitude (Brecker, 1984; Rokeach, 1968; Rosenberg \& Hovland, 1960; Zanna \& Rempel, 1988) that involves behavioral, cognitive and affective domains, others have chosen to embrace a dual-component model (Ajzen \& Fishbein, 1977; Ferguson et al., 2007; Keating et. al.., 2002; Keating, Guan, Ferguson, Chen \& Bridges, 2008;

Subramaniam \& Silverman, 2000) that includes the affective and cognitive domains. The dual-component model has become the most frequently used in physical education research as it has demonstrated strong consistency in measuring attitude, whereas the multi-component model has demonstrated a lack of consistent relationship between the behavioral domain and the measured attitude (Subramaniam \& Silverman, 2007). Utilizing the dual-component model of attitude, based on previous research, provides the most valid and reliable measure for attitude and allows sound conclusions to be made concerning attitude and its relationship to important variables.

In the dual-component model of attitude, the affective component measures the degree of emotional attraction or feeling toward an attitude object, while the cognitive component measures the beliefs about the characteristics (e.g., importance and usefulness of fitness tests and test results) of the attitude object (Keating \& Silverman, 2004a; Subramaniam \& Silverman, 2007). For example, in the context of physical education, the individual with both a positive feeling toward and a positive belief about the 
usefulness of physical activity is likely to consider engaging in regular physical activity. Conversely, the individual who holds a negative feeling about physical activity and a negative belief about its usefulness is likely to abstain from engaging in physical activity.

\section{Teacher Attitude Research and Fitness Testing}

Research in physical education supports that the teacher, curriculum, and instruction contribute to student attitude and engagement in the learning process (Bernstein, Phillips, \& Silverman, 2011; Castelli \& Rink, 2003; Placek et al., 1995; Solmon, 2003; Subramaniam \& Silverman, 2000, 2007). Recently, researchers have begun to investigate teachers' attitudes toward physical fitness testing (Mercier et al., 2016; Ferguson et al., 2007; Keating \& Silverman, 2004a; Keating \& Silverman, 2009) and have found support that teachers' attitudes toward fitness tests play an important role in the administration and use of fitness tests (Ferguson et al., 2007; Keating \& Silverman, 2004b; Keating \& Silverman, 2009; Stewart Stanec, 2009). Research also shows that overall teacher attitudes toward fitness tests are at best only moderately positive (Ferguson et al., 2007; Keating \& Silverman, 2009).

Previous experience. One important factor that the research shows influences an individual's feeling toward an object and his or her use of knowledge concerning the object is the experiences from past events (Calderhead \& Robson, 1991; Goodman, 1988; Hopple \& Graham, 1995; Keating et al., 2002). Nespor (1987) found that beliefs not only are created and formed from experience but also play a key role in teacher practices. Previous experiences in the context of sport and physical education has been found to 
influence curriculum (Rovegno, 1993, 1995), planning of tasks (Doolittle, Dodds, \& Placek, 1993; Placek et al., 1995), and teacher attitudes toward fitness tests (Keating et al., 2002). Moreover, early experiences are the foundation of belief and thus highly resistant to change (Pajares, 1992), even when clear and convincing evidence suggests that a belief was formed erroneously based on incorrect or incomplete knowledge and behavior.

The existing research on teachers' attitude toward fitness testing supports that many teachers' negative experiences with fitness tests (Hopple \& Graham, 1995; Keating et al., 2002), either during childhood or adulthood, influence their attitudes toward fitness tests. Keating and her colleagues (2002) discovered that a majority of pre-service teachers in physical education did not believe fitness tests were important or useful. The same study also showed that teachers who have had a negative experience with fitness tests as a student, often have negative attitudes toward the fitness tests as an adult (Keating et al., 2002). Negative experiences with fitness tests often deal with the public nature of the event, the physical pain and discomfort associated with tests (Hopple \& Graham, 1995), and the use of test results to grade students in physical education. While the number of studies on this area of investigation is limited it appears that teachers with positive attitudes toward fitness testing likely had positive experiences with fitness tests as a child or at some point in their life prior to becoming a teacher.

Professional development. Research suggests that professional development experiences for teachers are correlated with student performance (Mitchell, Castelli, \& Strainer, 2003). In physical education, a lack of professional preparation (McKenzie \& 
Sallis, 1996; Whitehead, 1989) and in-service training opportunities (Conkle, 1997) on the administration and appropriate use of fitness tests have been cited, making professional preparation and continuing professional development possible contributing factors to the neutral attitudes that physical educators have toward fitness tests. Furthermore, research on teacher attitude toward fitness tests has discovered a lack of understanding among physical education teachers as to the purpose of fitness tests (Keating et al., 2002), which may also contribute to the neutral attitudes toward fitness tests that teachers hold. These neutral and less than positive attitudes toward fitness tests by teachers may be contributing to students' attitude toward fitness, their experience with fitness instruction and learning, and ultimately engagement with the types of physical activity that can lead to improved performance on fitness tests.

School context. School context variables, including grade level, class size, available equipment, and adequate facilities, have been described as influencing factors on teachers' attitudes and instructional behaviors (Ferguson et al., 2007; Keating, 2003; Kulinna \& Silverman, 2000). Oversized classrooms and lack of adequate equipment and facility space may limit the opportunities for a teacher to reach all students through learning activities and, as a result, limit student opportunities to engage in learning and physical activity (Hastie \& Saunders, 1991).

\section{Summary}

A person's attitude is the positive or negative feeling that $\mathrm{s} /$ he has toward a behavior. Ajzen \& Fishbein's (1980) theory of reasoned action (TRA) advances the idea 
that behavioral intention is a function of an individual's attitude toward a behavior and the attitude of others toward the same behavior. In extending the TRA, the theory of planned behavior proposes that one's behavior is determined by a combination of one's behavioral beliefs, normative beliefs and control beliefs (Ajzen, 1989). Both theories consider attitude to be essential in the behavioral intention that an individual has to perform or carry out a behavior.

Research on teachers' attitudes toward fitness tests reveal neutral to slightly positive attitudes (Ferguson et al., 2007; Keating \& Silverman, 2004a; Keating \& Silverman, 2009; Melendez, 2004). The research supports that teachers with positive attitudes toward fitness tests tend to incorporate the recommended use of fitness tests more frequently (Mercier et al., 2016). The limited evidence available, however, warrants further investigation on teachers' attitudes and how teachers actually perceive fitness tests (Keating \& Silverman, 2004b). Such investigation will shed light on whether or not attitude influences both teachers' behavior and student performance. The gap that currently exists between current professional practice and recommended practice for use of fitness tests can, perhaps, be lessened to the point that fitness tests have an educational purpose in the physical education curriculum. As scholars in physical education have noted (Silverman et al., 2008), fitness testing has the potential to promote physical activity and improve health-related fitness only when fitness testing is used as an educational tool. 


\section{Teacher Behavior and Student Learning}

\section{Teacher Attitude and Behavior Research}

General education. Research shows that teachers' attitudes significantly influence their behavior (Bai \& Ertmer, 2008; Brickhouse, 1990; Lumpe et al., 1998; Lumpe et al., 2012). More specifically, several studies (Cronin-Jones, 1991; Haney, Czerniak, \& Lumpe, 2002; Hollon \& Anderson, 1987; Jones \& Carter, 2007; Verjovsky \& Waldegg, 2005; Windschitl \& Sahl, 2002) have found that teachers' attitudes toward a behavior is a great predictor of their intention to behave or act (Crawley, 1990; Haney et al., 1996; Mansour, 2009). One factor that the research has found to contribute to teachers' attitudes and behavior is experience. The pedagogical behaviors of experienced teachers have been found to be consistent with their attitudes and beliefs while beginning teachers' behaviors and attitudes have been found to be inconsistent (Cronin-Jones, 1991; Hollon \& Anderson, 1987). Other factors cited in the literature, as contributing to teachers' attitudes and subsequently teachers' behaviors and pedagogical practices, are contextual factors, such as school culture (Brown \& Melear, 2006; Windschitl \& Sahl, 2002).

Physical education. In physical education, teachers' curricular and instructional decisions are affected by their belief systems (Eisner \& Vallance, 1974; Ennis, 1992; McNeil, 1990; Pajares, 1992). Teachers' attitudes and values toward teaching comprise their educational value orientations (Kulinna \& Silverman, 2000). These value orientations play an important role in curriculum decision making by influencing a 
teacher's curriculum content priorities (Ennis, 1992, 1994b; Placek \& Dodds, 1988) and ultimately teacher action and behavior.

Physical education professionals have identified five value orientations as representative of teachers' attitudes and values toward teaching (Ennis, 1992; Jewett, Bain \& Ennis, 1995). The five value orientations are discipline mastery (McNeil, 1990), learning process (Papert, 1980), self-actualization (Maslow, 1979), social reconstruction (Apple, 1982), and ecological integration (Dewey, 1916). Research on teachers' value orientations shows that their value priorities influence what they teach, how they teach, and the learning experiences of the students in their classroom (Chen \& Ennis, 1996; Ennis, 1992). While teachers' value orientations generally guide the teaching and learning process that takes place in their classrooms, contextual barriers (i.e., student characteristics, lack of equipment, class size, etc.) often play a role and limit a teachers' ability to develop a curriculum consistent with their value orientation and reach intended curricular goals (Ennis, 1995, 1996; Kulinna \& Silverman, 2000; Zhu, Mahar, Welk, Going, \& Cureton, 2011). Even so, the research on teachers' value orientation (Ennis, 1992, 1994b; Ennis \& Chen, 1993, 1995, 1996; Ennis, Chen, \& Ross, 1992; Ennis \& Zhu, 1991) establishes that teachers oftentimes act in a manner consistent with their value orientation.

Overall, there is a paucity of research available on the relationship between teachers' attitude and behavior in physical education (Mercier et al., 2016). The research that is available, however, suggests that a positive relationship exists between teachers' attitudes and their behavior. Recent research by Mercier and his colleagues (2016) shows 
that a positive relationship exists between teachers' attitudes and teachers' use of fitness tests. Specifically, teachers with a more positive attitude toward fitness tests were found to teach students to self-assess, a recommended suggestion for the proper use of fitness testing as a part of a fitness education program (Silverman et al., 2008). This finding supports the contention held by researchers (Keating \& Silverman, 2004b) that teachers with positive attitudes toward fitness testing use fitness testing differently than those with negative attitudes.

\section{Teacher Behavior Research and Student Learning}

General education. Teacher effectiveness research in education has received widespread attention in education research (Brophy \& Good, 1986; Fraser, Walberg, Welch, \& Hattie, 1987; Lumpe et al., 2012; Wayne \& Young, 2003). Given this close attention and study, the research has revealed that a relationship between teachers' behavior and student learning does exist. In providing validation that teachers' behavior positively impacts student learning, both teachers' pedagogical practices and background have been found to influence student learning (Doyle, 1978, 1979, 1983; Good et al., 1975; McConnell, 1977; Murnane \& Phillips, 1981; Wenglinsky, 2002, 2003). More specifically, data-driven feedback and instruction (Fraser et al., 1987; Rosenshine, 1983), effective management strategies (Brophy \& Good, 1984), providing appropriate practice (Brophy \& Good, 1984; Rosenshine, 1983) and teacher expectation (Brattesani, Weinstein, \& Marshall, 1984; Brophy \& Good, 1986; Good, 1987) are factors that the research has found to have a positive relationship with student learning, even in the 
presence of contextual factors (e.g., parental involvement, class size, etc.) that often constrain a teacher's influence on learning.

Physical education. The primary goal in physical education is student learning. Much the same as in general education, there are many variables (Ennis, 1992), to include student characteristics (Rikard, 1992; Silverman, 1993) and contextual factors (Ennis, 1992, 1995), which contribute to student learning in physical education. Still, instructional (Bernstein et al., 2011; Metzler, 1989; Rink, 1994; Silverman, 1985, 1990; Silverman, Kulinna, \& Crull, 1995) variables are critically important. In both motor learning and physical education research, cognitive processes play an important role in motor performance (French, Rink, \& Werner, 1990; Sweeting \& Rink, 1999). Research (Good \& Magill, 1986; Lee et al., 1994) supports that teachers facilitate cognitive processing by the way they arrange learning and practice tasks.

Skill progression (French et al., 1991), accountability (Lund \& Shanklin, 2011), and task presentation (Kwak, 1993; Silverman et al., 1995) all have been identified in the research as having an association with student learning and performance, but no relationship has been as strong as the positive relationship found between student learning and appropriate practice trials (Bernstein et al., 2011; Metzler, 1989; Silverman, 1985, 1990). Students who spend time in appropriate practice tasks related to a specific learning objective are more likely to see improvement (Magill, 2001). Moreover, the research (Bernstein et al., 2011; Metzler, 1989; Silverman, 1985, 1990, 1993, 2005) shows the importance of time in combination with appropriate practice as a critical component in student learning. The importance of providing students with not only 
appropriate tasks but also providing them with enough time to engage in activities is clearly established by these studies. The teacher directs the important responsibility of shaping the learning environment and designing the tasks that will allow students to practice, learn, and improve their understanding and performance.

\section{Summary}

Teachers' curricular and instructional decisions are affected by their belief systems (Eisner \& Vallance, 1974; Ennis, 1992; McNeil, 1990; Pajares, 1992). Value orientation, teaching experience, and school culture are factors that the research has found to contribute to teachers' attitudes and behavior. Teacher behavior and student learning research highlights diverse evidence on the relationship and provides data to support that teacher behavior consistently correlates with student achievement (Brophy \& Good, 1986; Doyle, 1978, 1979, 1983; Good et al., 1975; McConnell, 1977; Murnane \& Phillips, 1981; Rosenshine, 1971; Rosenshine \& Furst, 1973; Wenglinsky, 2002, 2003). This evidence identifies learning climate, skill progression, task presentation, accountability, and appropriate practice opportunities as key factors in student learning. Teachers and teachers' behavior play a critical role in student learning and performance.

\section{Summary}

In education, evaluation, assessment, and accountability are vitally important to the learning process as well as necessary for the continuous improvement of curriculum 
and instruction (Huba \& Freed, 2000). While accountability has taken on a greater role in $21^{\text {st }}$ century American education, starting with the No Child Left Behind (NCLB) Act and now continuing with Common Core State Standards (CCSS), educators and those with an interest in education must be mindful of the instruments and measures being used to account for student learning and how these measurements are being administered. With respect to physical education in American schools, one measurement in particular that has a long history is fitness testing (Brace, 1947; Landwer, 2009; McCloy \& Young, 1954). When used appropriately, fitness testing can be highly beneficial and result in student learning (Cale, Harris, \& Chen, 2007; Corbin, Pangrazi, \& Welk, 1995; Franks, Morrow, \& Plowman, 1988; Harris \& Cale, 2006; Silverman et al., 2008; Whitehead, Pemberton, \& Corbin, 1990). Conversely, when used inappropriately, fitness testing can lead to negative outcomes including physical inactivity and unfavorable attitudes toward physical activity (Hopple \& Graham, 1995; Keating, 2003).

Attitude, an individual's positive or negative belief toward an object and the evaluation of a behavior associated with this belief (Ajzen, 1991; Fishbein \& Ajzen, 1975), has been studied extensively, both in general and physical education, and found to have an important relationship to behavior (Ajzen \& Fishbein, 1977; Ferguson et al., 2007; Keating et al., 2002; Keating, Ferguson, Chen \& Bridges, 2008; Subramaniam \& Silverman, 2000). Though limited, research on teachers' attitudes toward fitness testing reveals neutral to slightly positive attitudes (Ferguson et al., 2007; Keating \& Silverman, 2004a; Keating \& Silverman, 2009; Melendez, 2004), providing evidence of a potentially important relationship with student learning and performance in physical education. 
Knowing that teachers' curricular and instructional decisions are affected by their belief systems (Eisner \& Vallance, 1974; Ennis, 1992; McNeil, 1990; Pajares, 1992), it is reasonable to assume, given the low levels of physical activity among adolescent youth, that teachers' attitudes toward fitness testing may have an important relationship student performance on fitness tests.

Physical activity begins to decline after adolescence, with most youth not achieving the recommended levels of moderate-to-vigorous physical activity (MVPA) (CDC, 2009; Fairclough, Beighle, Erwin, \& Ridgers, 2012; Troiano et al., 2008). The 2012 National Health and Nutrition Examination Survey (NHANES) and the NHANES National Youth Fitness Survey data show one-quarter (24.8\%) of youth are engaged in moderate-to-vigorous physical activity for at least 60 minutes daily (Fakhouri et al., 2014). This statistic, along with the literature in both general and physical education that shows teachers' curricular and instructional decisions impact student learning (Doyle, 1978, 1979, 1983; Good et al., 1975; McConnell, 1977; Murnane \& Phillips, 1981; Wenglinsky, 2002, 2003), suggests that more research on teachers' attitudes toward fitness testing is needed in order to identify the relationship that exists between teachers' attitudes and student learning and performance.

From what we know about teaching and learning from the literature, it is clear that teachers and teachers' behavior play a critical role in student learning and performance (Brattesani et al., 1984; Brophy \& Good, 1986; Doyle, 1978, 1979, 1983; Fraser et al., 1987; Good et al., 1975; McConnell, 1977; Murnane \& Phillips, 1981; Rosenshine, 1983; Wenglinsky, 2002, 2003). Since teachers' attitudes play a role in the 
selection of content and their instructional practices (Crawley, 1990; Eisner \& Vallance, 1974; Ennis, 1992; Kulinna \& Silverman, 2000; Mansour, 2009; McNeil, 1990; Pajares, 1992), an assumption can be made that teachers' attitudes, also, contribute to student learning and performance. To date, only one study has investigated the relationship between teachers' attitudes toward fitness testing and student performance on fitness tests (Melendez, 2004) and this study was conducted with elementary school teachers and students. Fitness testing has the potential to promote physical activity and improve health-related fitness if it is used as an educational tool (Silverman et al., 2008). This study on urban middle school physical education teachers would be the first study to examine the relationship between middle school teachers' attitudes toward fitness testing and students' performance on fitness tests.

The purpose of this study was to investigate the attitudes of urban middle school physical education teachers toward fitness tests, and to examine the relationship between urban middle school physical education teachers' attitudes toward fitness tests and student performance on fitness tests. 
Chapter III

METHODOLOGY

\section{Instrumentation}

\section{Survey Instrument for Teachers}

A survey instrument consisting of two parts was distributed to participants through Qualtrics, an online survey tool. The researcher used Qualtrics to collect demographic and attitudinal data from a sample of urban, middle school physical education teachers. The first part of the survey consisted of demographic items (i.e., gender, experience, etc.), developed through pre-pilot and pilot testing, on teachers' background and profession-related variables (Appendix A). The second part of the survey, measuring teachers' attitudes toward fitness tests, was comprised of the Physical Education Teacher Attitudes toward Fitness Tests Scales (PETAFTS) (Keating et al., 2008) (Appendix B).

\section{Demographic Questionnaire}

The demographic questionnaire section of the survey instrument was developed in two stages: pre-pilot and pilot. During the pre-pilot stage of development, the researcher relied on content from previous studies (Ferguson et al., 2007; Keating \& Silverman, 2004a; Melendez, 2004) and the research literature on teachers' attitudes toward fitness 
tests (Keating et al., 2008; Keating \& Silverman, 2004a, 2009) to prepare demographic questionnaire items.

Pre-pilot study. The purpose of the pre-pilot study was to obtain feedback on the content and clarity of the proposed demographic questionnaire. Ten experienced physical educators in a graduate-level physical education seminar completed the pre-pilot questionnaire and provided recommendations for improvement. After addressing the recommendations provided by the seminar group, a revised questionnaire was converted into an online questionnaire, along with the second part of the survey instrument, for further pilot testing.

\section{PETAFTS}

The PETAFTS developed by Keating \& Silverman (2004a) and modified by Keating et al., (2008) is a 15-item questionnaire that rates responses on a 7-point, Likerttype scale to measure the affective and cognitive attitude domains. The scale consists of nine items in the affective domain and six items in the cognitive domain. The affective domain consists of two subdomains (i.e., enjoyment of implementing fitness tests and enjoyment of using fitness tests) while the cognitive domain consists of only one domain (i.e., beliefs in the usefulness of the test results). To avoid response bias, the PETAFTS contains negatively worded items in the scale. An example of an item that is negatively worded is, "I dislike using the results of my students' fitness tests to modify my physical activity/fitness instruction." These negatively worded items are reverse scored during data analysis. A higher score on the individual scales (i.e., 1 for strongly disagree, 7 for 
strongly agree, and 4 for neutral) as well as the overall combined scale represent a stronger endorsement of fitness tests (Keating et al., 2008).

The PETAFTS scores have been previously validated (Keating \& Silverman, 2004a) and cross-validated (Keating et al., 2008) to test the overall attitudes of teachers as well as their attitudes in the affective and cognitive domains. Construct validity for the original PETAFTS from the structural equation model (SEM) indicated acceptable goodness-of-fit indices $(\mathrm{RMSEA}=.09, \mathrm{GFI}=.98, \mathrm{RMSR}=.07)$. Similarly, SEM results for the modified PETAFTS produced good fit indices $($ RMSEA $=.07, \mathrm{GFI}=.91$, RMSR $=.07$ ). Using Cronbach's alpha, reliability scores for overall, affective, and cognitive domains on both validation and cross-validation studies were greater than 0.70 (Keating \& Silverman, 2004a; Keating et al., 2008), indicating acceptable reliability. The factor loading for each item on the scale was greater than 0.30 , supporting the items as good indicators of the factors they are measuring. Figure 1 provides a visual representation of the scale and items in each domain. 


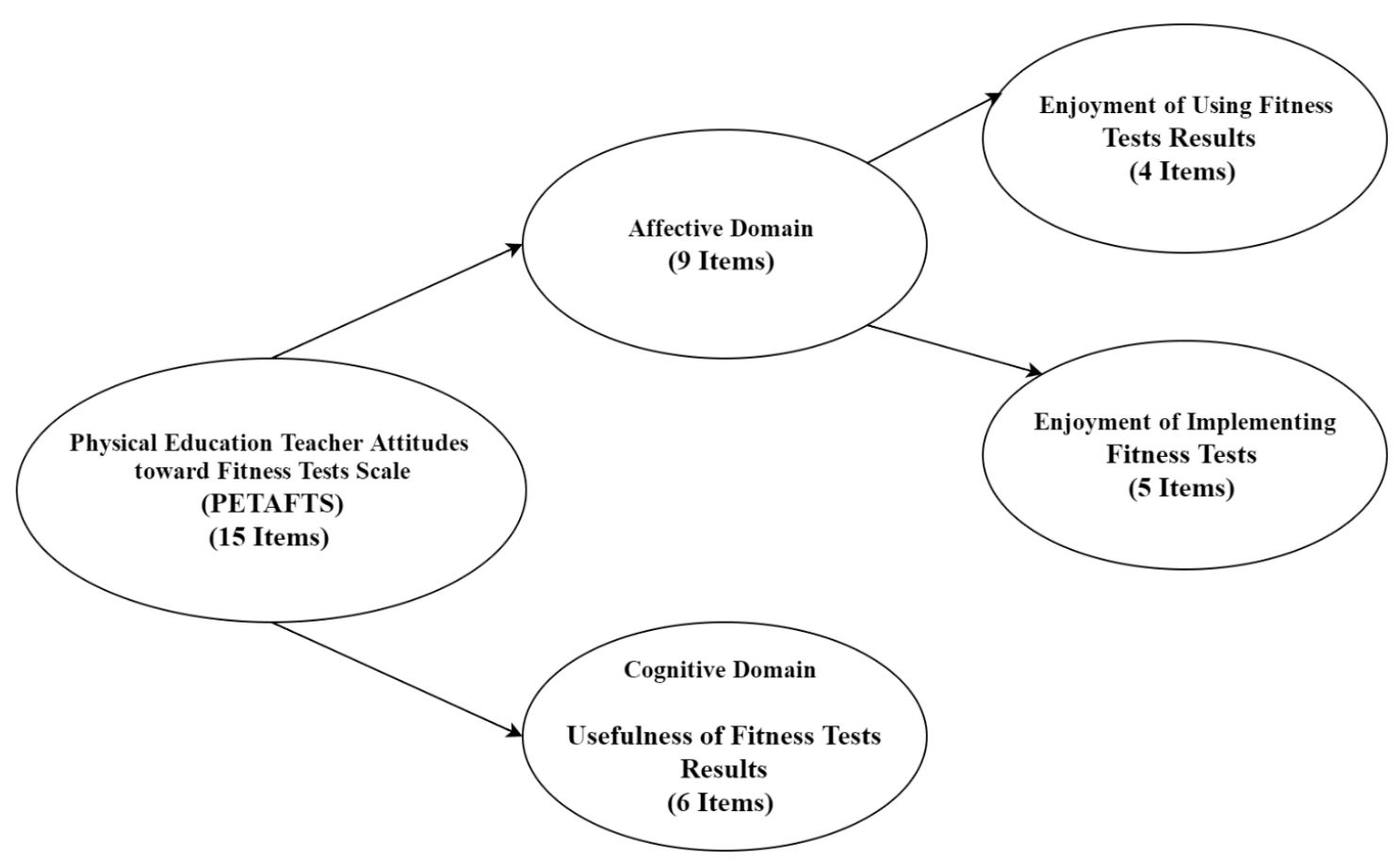

Figure 1. Model of PETAFTS (Adapted from Keating et al., 2008).

\section{Placing Survey Online and Pilot Testing}

The survey instrument was placed on the online survey software Qualtrics (https://tccolumbia.qualtrics.com). Prior to pilot testing, the survey was extensively edited by the researcher to ensure that it was engaging, functional, and ready for testing.

Pilot study. The pilot survey was distributed to a convenience sample of middle school physical education teachers for testing and improvement. The researcher obtained email lists from his peers in physical education administration. After receiving the email lists, the researcher emailed an invitation letter (Appendix C) to all recipients on the lists requesting their participation and assistance with the study. The purpose of the pilot 
study was to obtain feedback on the survey procedures, questions, functionality, and attractiveness.

Twenty-three certified physical education teachers participated in the pilot study. Participants represented males and females, teachers teaching sixth, seventh, and eighth grades, and teachers with varying degrees of experience and education. The participants followed a hyperlink contained in the email invitation letter to complete the survey and provide feedback (i.e., clarity of survey questions and survey experience) to help improve the survey. Based on the responses and feedback from the pilot survey participants, minor changes were made to the survey instrument, including the wording and graphical positioning for a few questions on the survey. Overall, pilot study participants found the survey to be complete, engaging, and straightforward.

\section{FITNESSGRAM®}

The FITNESSGRAM® fitness assessment (FitnessGram®, 2007) consists of a six test-battery (with corresponding measures) to measure an individual's health-related fitness: body composition (skinfold measurements or BMI), aerobic capacity (mile run or PACER), upper body strength and endurance ( $90^{\circ}$ push-ups or modified pull-up), abdominal strength and endurance (curl-up), trunk extensor strength and flexibility (trunk-lift), and flexibility (shoulder stretch or sit-and-reach). The three field tests used in FITNESSGRAM® to measure aerobic capacity are the (a) PACER (Progressive Aerobic Cardiovascular Endurance Run), (b) One-Mile Run, and (c) a walk test (for adolescents 13 years of age or older) (Plowman et al., 2013). Field tests used to measure 
muscular strength, muscular endurance, and flexibility are the (a) curl-up, (b) trunk lift, (c) $90^{\circ}$ push-up, (d) modified pull-up, (e) flexed arm hang, (f) back-save sit and reach, and $(\mathrm{g})$ shoulder stretch. In this study, five of the six tests will be used to measure student fitness performance. Performance scores from the PACER, push-up, curl-up, sitand-reach, and trunk-lift tests will be used to study fitness performance. BMI will not be included because it is an anthropometric measure of body size and physical parameters rather than a measure of fitness performance.

The FITNESSGRAM ${ }^{\circledR}$ results are evaluated against criterion-referenced standards (CRS), called Healthy Fitness Zones, to determine a student's fitness level (Plowman et al., 2013). Student performance on the tests are classified into one of three levels: (a) Healthy Fitness Zone (HFZ), (b) Needs Improvement Zone (NIZ), or (c) Needs Improvement - Health Risk (NI-HRZ). An established cut-off point determines the level into which a student fits. Overall, scores from the FITNESSGRAM® have proven to be a highly valid and reliable instrument (Hartman \& Looney, 2003; Ihmels, Welk, McClain, Schaben, 2006; Lobelo, Pate, Dowda, Liese, \& Ruiz, 2009; Morrow, Martin, \& Jackson, 2010).

\section{Study}

The procedures for this study consisted of three phases. In phase 1, institutional review board (IRB) approval was obtained from Teachers College, Columbia University 
and the school districts in which the study was be carried out. Phase 2 involved participant recruitment and 18 months of data collection. Finally, phase 3 entailed data management, data analysis, and the communication of the results.

\section{Institutional Review Board (IRB) and Protection of Human Subjects}

IRB approval was received from Teachers College, Columbia University and the school districts in which the study was carried out. All participants were presented with and electronically signed a participant's rights and consent form (Appendix D) prior to commencing the study.

\section{Participant Selection}

Middle school physical education teachers $(\mathrm{N}=124)$ from five urban school districts throughout the United States were the participants in the study. There were 42.7\% females and $56.5 \%$ males in the study. More than half of the participating teachers $(70.2 \%)$ held a Masters degree, participated in continuing professional development on fitness testing, and taught three grades $\left(6^{\text {th }}, 7^{\text {th }}, 8^{\text {th }}\right)$ at the middle school level. Inclusion criteria for the teachers included (a) certification in physical education, (b) teaching middle school physical education, and (c) administration of FITNESSGRAM ${ }^{\circledR}$. The researcher contacted school district administrators from the five urban school districts to explain the study's purpose and to request approval and consent for having their district participate in the study. An invitation letter describing the study (Appendix E) and an administrator's right and consent form (Appendix F) was 
then emailed to the administrators for their district's written consent to participate in the study.

\section{Participant Recruitment}

The method for recruiting study participants occurred in three phases in order to draw a sample that was sufficiently large and provided strength to the study's results. In phase 1 , the researcher used his personal contacts $(\mathrm{N}=19)$ to create an email list and recruit urban middle school physical education teachers from the five urban school districts for participation in the study. The researcher sent each teacher on the email list an invitation letter, containing a description of the study, along with a hyperlink to the online survey.

In phase 2, the researcher sent a formal email to the Research Data Officer of the participating school districts requesting permission to either (a) obtain an email list of middle school physical education teachers in their district or (b) forward an email invitation letter to their middle school physical education teachers. Once permission was received, the researcher sent an email invitation letter to the appropriate individuals $(\mathrm{N}=$ 594). The email contained a description of the study along with a hyperlink to the study for those wishing to participate. It is possible that some teachers may have received multiple email invitation letters.

Phase 3 consisted of follow-up emails to teachers who had yet to complete the survey and who had not indicated that they did not wish to participate in the study. After 30 days, a second email was sent to teachers on the list requesting their participation in 
the survey. Finally, after 60 days from the initial email invitation letter, a final email was sent reminding any teacher on the list who had not completed the survey to please do so. These follow-up email reminders were intended to increase survey response rate and provide strength to the study.

\section{Distribution of Survey Instrument to Participants}

Participating physical education teachers electronically signed the informed consent prior to beginning the survey. Teachers completed the survey instrument in one sitting. The time window for completing the online survey was eight weeks.

\section{Obtaining Student FITNESSGRAM® Scores}

The researcher obtained student data on physical fitness tests scores by grade, age, gender, and other demographic variables that are summarized in Appendix G. These data were attained by submitting a data request through the research and policy support group of the school districts included in the study. Prior to obtaining physical fitness test scores, the researcher submitted a list of all teachers who had completed the online survey and consented to participating in the second part of the research study, electronic copies of their consent, and a unique ID number for each teacher. The unique teacher ID number was used to accurately match surveyed teachers to their students' unique ID number and physical fitness test score data. Data for each individual student was obtained using a unique identification number in order to ensure anonymity. Due to the difficulty of involving a large number of parents in the research study and the ready 
availability of FITNESSGRAM $®$ data, which are current records in the five school districts, parental consent was not required in order to access the fitness score data.

\section{Data Management}

When the time window for survey response had closed, the researcher carried out a careful data cleaning and reduction process to assure that all data collected was accurate and prepared for analysis. Prior to uploading the participant survey data from Excel into SPSS, the researcher reverse coded negative items in the PETAFTS to ensure an accurate representation of teachers' affective, cognitive, and overall attitude scores. The process that was used to manage and analyze the data is described in further detail below and includes the following three parts: (a) management of participation list; (b) management of FITNESSGRAM ${ }^{\circledR}$ data; and (c) data analysis.

Management of participation list. All teachers participating in the study were assigned a unique identification number to maintain their anonymity and to ensure an accurate matching of teacher survey data to students' fitness tests performance data. The researcher securely transferred the complete participant list to each school district's research group once the survey had closed and all teacher responses had been compiled, downloaded, and entered from Qualtrics into Microsoft Excel. Next, participating school districts prepared a FITNESSGRAM ${ }^{\circledR}$ student performance file of the students whose teachers consented to participate in the second part of the study. The school district research group for each district then securely transfer the encrypted electronic file to the researcher's institutional email. 
Management of FitnessGram ${ }^{\circledR}$ data. For this study, the school districts provided the researcher with student unique identification number, student demographic data (i.e., age, grade, gender, race, etc.), and scores from the FITNESSGRAM®. Appendix G provides a complete list and description of the student data fields that were requested for districts participating in the study. Upon receipt of the data, the researcher uploaded it into SPSS to accurately match student and teacher data. Additionally, new unique variables were created for fitness level categories (i.e. HFZ, NIZ, NIHR-Z). Fitness level categories were established for each teacher by the creation and operation of a formula in SPSS.

\section{Data Analysis}

For this study, individual teachers were the unit of analysis. Teachers' attitude data were matched with their students' FITNESSGRAM® data after uploading both the attitude and fitness performance information into SPSS. Then, all data were analyzed to answer the primary and secondary research questions. The two affective subcomponents (i.e., enjoyment of implementing fitness test results and enjoyment of using fitness test results) scores were calculated by summing the mean of the items in each subcomponent. Next, teachers' overall affective component scores were calculated by summing the mean of the two affective subdomain scores. Teachers' cognitive component scores was calculated by summing the mean of the six items in the one cognitive subdomain (i.e., usefulness of fitness test results). Overall teachers' attitudes were the mean of the summed affective and cognitive components. 
Descriptive statistics. Responses collected from the survey were analyzed in SPSS. Descriptive statistics (i.e., frequency distributions, mean, range, and standard deviation) were calculated for teachers' demographic (i.e., gender, ethnicity, age, etc.) and professional (i.e., teaching experience, educational training, prior experience, etc.) variables, and for teachers' attitudes toward fitness tests. More specifically, descriptive statistics were calculated for overall attitude and attitude subscales for the entire sample as well as by gender, class size, teaching experience, and amount of professional development. In addition, descriptive statistics (i.e., frequency distributions, mean, range, and standard deviation) were calculated for students' test performances.

Inferential statistics. Several multivariate analyses of variances (MANOVAs) and analyses of variances (ANOVAs) were performed to examine the differences in the three attitude subdomain variables by demographic variables. A years teaching experience by gender MANOVA was performed on the three attitude subdomain variables. A separate MANOVA was performed on the three attitude subdomain variables by teachers' age. Significant MANOVAs were followed by stepwise discriminant function analysis (DFA). An ANOVA was performed on the first variable to enter the DFA, followed by an analysis of covariance (ANCOVA) for subsequent variables that entered the DFA (Stevens, 2009). The Bonferroni post-hoc follow-up was performed on the adjusted means. An ANOVA on overall teacher attitudes was performed to examine differences by teacher degree level.

Correlational statistics. In addition to descriptive and inferential statistics, correlational statistics, Pearson Product Moment Correlations, were used to determine the 
relationship between teachers' attitude toward fitness tests and their student's performance on fitness tests. Each component of attitude (i.e., affect and cognition) were correlated with student scores from the FITNESSGRAM ${ }^{\circledR}$ test. Relationships between (a) overall teachers' attitudes and the percentage of students in the HFZ on various components of the FITNESSGRAM®; (b) overall teachers' affective attitudes and the percentage of students in the HFZ on various components of the FITNESSGRAM®; (c) teachers' enjoyment of using fitness test results and the percentage of students in the HFZ on various components of the FITNESSGRAM®; (d) teachers' enjoyment of implanting fitness tests and the percentage of students in the HFZ on various components of the FITNESSGRAM®; (e) teachers' beliefs about the usefulness of fitness test results and the percentage of students in the HFZ on various components of the FITNESSGRAM ${ }^{\circledR}$ were studied. 


\section{Chapter IV}

\section{RESULTS}

The purpose of this study was to investigate the attitudes of urban middle school physical education teachers toward physical fitness tests. A second purpose of this this study was to examine the relationship between urban middle school teachers' attitudes toward fitness testing and student performance on fitness tests. Through descriptive and correlational statistics, urban middle school physical education teachers' attitudes and the relationship between their attitudes and students' performance on fitness tests were analyzed. This chapter discusses the results of the entire sample of teachers' attitudes toward fitness tests, the sample with fitness tests scores descriptive statistics, and the relationships between teachers' attitudes toward fitness tests and student performance on fitness tests.

\section{Entire Sample Teachers' Attitudes}

Teachers' overall attitudes toward fitness testing were just higher than neutral, signaling positive attitudes. The mean for all teachers was $66.74($ s.d. $=17.83)$ out of a possible total score of 105. Teachers' attitude mean scores for the cognitive and affective subdomains also were positive. Teachers' affective attitude toward fitness testing was 40.72 (s.d. $=11.10)$ out of a possible 63. For the affective subdomain of enjoyment of 
implementing fitness tests the mean score for all teachers was 21.66 out of a possible 35 .

For the affective subdomain of enjoyment of using fitness tests results the mean score for all teachers was 19.06 out of a possible 28. Finally, the cognitive subdomain measuring teachers' attitudes toward the usefulness of fitness tests results produced a mean score of 26.02 out of a possible 42. See Table 1 for descriptive statistics on teachers' attitudes toward fitness tests.

Table 1

Teachers' Attitudes toward Fitness Tests Descriptive Statistics

\begin{tabular}{llllll}
\hline & $\begin{array}{l}\text { Overall } \\
\text { Attitude }\end{array}$ & AD & AD-EIF & AD-EUF & CD \\
\hline Questions per Category & 15 & 9 & 5 & 4 & 6 \\
$\mathrm{~N}$ & 121 & 121 & 121 & 121 & 121 \\
Mean & 66.74 & 40.72 & 21.66 & 19.06 & 26.02 \\
Std. Deviation & 17.83 & 11.10 & 7.41 & 4.73 & 7.90 \\
\hline
\end{tabular}

Note. $\mathrm{AD}=$ Affective Domain, $\mathrm{EIF}=$ Enjoyment of Implementing Fitness Tests, EUF = Enjoyment of Using Fitness Tests Results, $\mathrm{CD}=$ Cognitive Domain.

The mean for female teachers was $64.77($ s.d. $=18.14)$ and the mean for male teachers was 67.84 (s.d. $=17.43$ ). Similar to all teachers, the attitude mean scores for both female and male teachers in the cognitive and affective subdomains also were positive. For overall, affective, and cognitive attitudes, male teachers had higher attitude scores than female teachers, although nonsignificant. See Table 2 for descriptive statistics on teachers' attitudes toward fitness tests by teachers' gender. 
Table 2

$\underline{\text { Teachers' Attitudes toward Fitness Tests by Gender Descriptive Statistics }}$

\begin{tabular}{lllllll}
\hline \multicolumn{5}{c}{ Female } & \multicolumn{7}{c}{ Overall } & & & & \\
& Attitude & AD & AD-EIF & AD-EUF & CD \\
\hline Male & N & 52 & 52 & 52 & 52 & 52 \\
& Sean & 64.77 & 39.29 & 20.87 & 18.42 & 25.48 \\
& SD & 18.14 & 11.06 & 7.32 & 4.75 & 8.44 \\
\hline & Mean & 68 & 68 & 68 & 68 & 68 \\
& SD & 17.43 & 41.57 & 22.13 & 19.44 & 26.26 \\
\hline
\end{tabular}

Note. $\mathrm{SD}=$ Standard Deviation, $\mathrm{AD}=$ Affective Domain, EIF = Enjoyment of Implementing Fitness Tests, EUF = Enjoyment of Using Fitness Tests Results, CD = Cognitive Domain.

Table 3

Teachers' Attitudes toward Fitness Tests by Degree Descriptive Statistics

\begin{tabular}{lllllll}
\hline & & $\begin{array}{l}\text { Overall } \\
\text { Attitude }\end{array}$ & AD & AD-EIF & AD-EUF & CD \\
\hline Bachelors & $\mathrm{N}$ & 35 & 35 & 35 & 35 & 35 \\
& Mean & 73.34 & 44.34 & 23.54 & 20.80 & 29.00 \\
& SD & 19.84 & 12.66 & 8.26 & 5.06 & 7.66 \\
\hline Masters & $\mathrm{N}$ & 86 & 86 & 86 & 86 & 86 \\
& Mean & 64.05 & 39.24 & 20.90 & 18.35 & 24.80 \\
& SD & 16.31 & 10.10 & 6.94 & 4.43 & 7.71 \\
\hline
\end{tabular}

Note. $\mathrm{SD}=$ Standard Deviation, $\mathrm{AD}=$ Affective Domain, $\mathrm{EIF}=$ Enjoyment of Implementing Fitness Tests, EUF = Enjoyment of Using Fitness Tests Results, CD = Cognitive Domain.

See Table 4 for descriptive statistics on teachers' attitudes toward fitness tests by teachers' age. 
Table 4

Teachers' Attitudes Toward Fitness Testing by Age Descriptive Statistics

\begin{tabular}{llllll}
\hline & & Overall & & & \\
& & Attitude & CD & AD-EIF & AD-EUF \\
\hline Millennials & $\mathrm{N}$ & 39 & 39 & 39 & 39 \\
& Mean & 68.74 & 26.92 & 22.36 & 19.46 \\
& Std. Deviation & 17.62 & 7.69 & 6.52 & 5.15 \\
\hline Gen X & $\mathrm{N}$ & 63 & 63 & 63 & 63 \\
& Mean & 64.84 & 24.51 & 21.46 & 18.87 \\
& Std. Deviation & 16.77 & 7.49 & 7.49 & 4.26 \\
\hline Baby Boomers & $\mathrm{N}$ & 19 & 19 & 19 & 19 \\
& Mean & 68.8947 & 29.1579 & 20.8947 & 18.8421 \\
& Std. Deviation & 21.66383 & 8.82712 & 9.01169 & 5.49002 \\
\hline Total & N & 121 & 121 & 121 & 121 \\
& Mean & 66.74 & 26.02 & 21.66 & 19.06 \\
& Std. Deviation & 17.83 & 7.90 & 7.41 & 4.73 \\
\hline
\end{tabular}

Note. $\mathrm{SD}=$ Standard Deviation, $\mathrm{AD}=$ Affective Domain, $\mathrm{EIF}=$ Enjoyment of Implementing Fitness Tests, EUF = Enjoyment of Using Fitness Tests Results, $\mathrm{CD}=$ Cognitive Domain.

\section{Differences in Attitude}

The years teaching experience by gender MANOVA performed on the three subdomain attitude variables found no significant differences by gender (Wilks' $\lambda=$ $0.981, F(3,111)=0.725, p>.05)$, years teaching experience $($ Wilks' $\lambda=0.921, F(6,222)=$ $1.553, p>.05)$, or the interaction between years teaching experience and gender (Wilks' $\lambda$ $=0.986, F(6,222)=0.268, p>.05)$. 
MANOVA results performed on the three subdomain attitude variables found significant differences by teachers' age (Wilks' $\lambda=0.869, F(6,232)=2.808, p<.05)$. The follow-up stepwise DFA confirmed the significant difference found between teachers' age. The first variable to enter the equation was the cognitive subdomain (Wilks' $\lambda=$ $0.952, F(2,118)=3.006, p=.053)$ followed by the affective subdomain of enjoyment of using fitness test results (Wilks' $\lambda=0.885, F(4,234)=3.687, p<.05$ ).

An ANOVA was performed on cognitive subdomain and an ANCOVA was performed with the affective subdomain of enjoyment as a covariate. The ANOVA $(F(2,118)=7.376, p<.001)$ and $\operatorname{ANCOVA}(F(3,117)=67.667, p<.001)$ confirmed the significant difference found between teachers' age for the cognitive subdomain and the affective subdomain of enjoyment of using fitness test results.

The Bonferroni post-hoc test on the adjusted means for the affective subdomain of enjoyment of using fitness test results found that teachers' in the 36 years of age to 50 years of age group (i.e., Gen X) had higher scores than teachers' in the 35 years of age and younger group (i.e., millennials), though not significant. Additionally, millennials had non-significantly higher scores than teachers' in the 51 years of age and older group (i.e., baby boomers). Finally, Gen X teachers had significantly higher adjusted affective subdomain of enjoyment of using fitness tests results scores than baby boomers.

An ANOVA on overall teacher attitudes found significant differences between teachers holding a Bachelors degree and teachers with a Masters degree $\left(F_{(1)}=7.11\right.$, $p<.01$ ) (Bachelors $\mathrm{M}=73.34$, s.d.=19.84 Masters $\mathrm{M}=64.05$, s.d.=16.31). 


\section{Sample with Fitness Tests Scores Descriptive Statistics}

\section{Teachers' Attitudes}

Teachers' overall attitudes toward fitness testing were just higher than neutral, signaling positive attitudes. The mean for all teachers was $65.57($ s.d. $=17.75)$ out of a possible total score of 105 . Teachers' attitude mean scores for subdomains of cognitive and affective were also positive. Teachers' affective attitudes toward fitness testing was 40.03 (s.d. = 11.09) out of a possible 63. For the affective subdomain of enjoyment of implementing fitness tests the mean score for all teachers was 21.26 (s.d. $=7.60$ ) out of a possible 35. For the affective subdomain of enjoyment of using fitness tests results the mean score for all teachers was 18.77 (s.d. $=4.77$ ) out of a possible 28. Finally, the cognitive subdomain measuring teachers' attitudes toward the usefulness of fitness tests results produced a mean score of 25.54 (s.d. $=7.95$ ) out of a possible 42 . See Table 5 for descriptive statistics on teachers' attitudes toward fitness tests.

\section{Table 5}

Teachers' Attitudes Toward Fitness Testing Descriptive Statistics

\begin{tabular}{llllll}
\hline & $\begin{array}{l}\text { Overall } \\
\text { Attitude }\end{array}$ & AD & AD-EIF & AD-EUF & CD \\
\hline Questions & 15 & 9 & 5 & 4 & 6 \\
$\mathrm{~N}$ & 74 & 74 & 74 & 74 & 74 \\
Mean & 65.57 & 40.03 & 21.26 & 18.77 & 25.54 \\
SD & 17.75 & 11.09 & 7.60 & 4.77 & 7.95 \\
\hline
\end{tabular}

Note. $\mathrm{SD}=$ Standard Deviation, $\mathrm{AD}=$ Affective Domain, $\mathrm{EIF}=$ Enjoyment of Implementing Fitness Tests, EUF = Enjoyment of Using Fitness Tests Results, $\mathrm{CD}=$ Cognitive Domain. 
The mean for female teachers was $64.76($ s.d. $=19.66)$ and the mean for male teachers was 66.09 (s.d. $=16.61)$. Similar to all teachers, the attitude mean scores for both female and male teachers in the cognitive and affective subdomains also were positive. For overall, affective, and cognitive attitudes, male teachers had more favorable attitudes than female teachers. See Table 6 for descriptive statistics on teachers' attitudes toward fitness tests by teachers' gender.

Table 6

Teachers' Attitudes Toward Fitness Testing by Gender

\begin{tabular}{lllllll}
\hline & & Overall & & & & \\
& & Attitude & AD & AD-EIF & AD-EUP & CD \\
\hline Female & $\mathrm{N}$ & 29 & 29 & 29 & 29 & 29 \\
& Mean & 64.76 & 39.24 & 20.55 & 18.69 & 25.52 \\
& SD & 19.66 & 12.13 & 8.09 & 5.22 & 9.07 \\
\hline Male & $\mathrm{N}$ & 45 & 45 & 45 & 45 & 45 \\
& Mean & 66.09 & 40.53 & 21.71 & 18.82 & 25.56 \\
& SD & 16.61 & 10.48 & 7.32 & 4.51 & 7.25 \\
\hline
\end{tabular}

Note. $\mathrm{SD}=$ Standard Deviation, $\mathrm{AD}=$ Affective Domain, $\mathrm{EIF}=$ Enjoyment of Implementing Fitness Tests, EUF = Enjoyment of Using Fitness Tests Results, CD = Cognitive Domain.

\section{Fitness Test Statistics}

The percentage of students in the HFZ on various components of the FITNESSGRAM® ranged between $45 \%$ and $68 \%$. The fitness test with the highest percentage of students in the HFZ was the Left Sit and Reach with 68.15\% (s.d.=22.74), while the PACER test had only $44.83 \%$ (s.d.=27.94) in the HFZ. See Table 7 for descriptive statistics on the percentage of students in the HFZ on various components of the FITNESSGRAM®. 
Table 7

Percentage of Students in HFZ on Various Components of FITNESSGRAM®

\begin{tabular}{llllll} 
& PACER & CU & PU & LSR & RSR \\
\hline $\mathrm{N}$ & 53 & 68 & 67 & 55 & 53 \\
\hline Mean & 44.83 & 66.82 & 51.50 & 68.15 & 67.81 \\
\hline $\mathrm{SD}$ & 27.94 & 23.29 & 21.28 & 22.74 & 22.27 \\
\hline
\end{tabular}

Note. $\mathrm{SD}=$ Standard Deviation, CU = Curl-Up, PU = Push-Up, LSR = Left Sit and Reach, RSR $=$ Right Sit and Reach .

The percentage of students in HFZ on various components of the FITNESSGRAM® by teachers’ gender found that students who had female physical education teachers passed the tests at a higher percentage than students who had male physical education teachers in all fitness test components. As with the percentage of students in HFZ on various components of the FITNESSGRAM® for all teachers, the fitness test with the highest percentage of students in the HFZ was the Left Sit and Reach for both female and male teachers, while the PACER test had the lowest percentage of students in the HFZ for both female and male teachers. See Table 8 for descriptive statistics on the percentage of students in the HFZ on various components of the FITNESSGRAM® by teacher gender. 
Table 8

Percentage of Students in HFZ Various Components of FITNESSGRAM® by Teacher Gender

\begin{tabular}{lllllll}
\hline & & Pacer & CU & PU & LSR & RSR \\
\hline & $\mathrm{N}$ & 20 & 27 & 26 & 20 & 19 \\
& Mean & 48.47 & 69.25 & 52.19 & 69.32 & 68.64 \\
Female & SD & 27.91 & 21.24 & 21.81 & 19.25 & 17.37 \\
\hline & $\mathrm{N}$ & 33 & 41 & 41 & 35 & 34 \\
& Mean & 42.63 & 65.23 & 51.07 & 67.48 & 67.34 \\
Male & SD & 28.15 & 24.68 & 21.20 & 24.75 & 24.83 \\
\hline
\end{tabular}

Note. $\mathrm{SD}=$ Standard Deviation, $\mathrm{CU}=\mathrm{Curl}-\mathrm{Up}, \mathrm{PU}=\mathrm{Push}-\mathrm{Up}, \mathrm{LSR}=$ Left Sit and Reach, RSR $=$ Right Sit and Reach.

\section{Relationships: Teachers' Attitudes and Student Performance on Fitness Tests}

Among the findings, the affective subdomain of teachers' attitude on the enjoyment of using fitness tests results was found to have a significant positive relationship with the percentage of students in the HFZ for the PACER test $[r(53)=.245$, $p<.05]$, the curl-up test $[r(68)=.214, p<.05]$, the push-up test $[r(67)=.344, p<.01]$, and the Right Sit and Reach test $[r(53)=.233, p<.05]$. For teachers' overall attitudes toward fitness tests, the only significant relationship found in the correlational analysis was with the percentage of students in the HFZ for the push-up tests $[r(67)=.203, p<$ .05]. Additionally, a statistically significant relationship was found between teachers' attitudes toward the usefulness of fitness test results and the percentage of students in the HFZ for push-up tests $[r(67)=.238, p<.05]$. A summary of all relationships can be found in Table 9. 
Table 9

\begin{tabular}{lllllll}
\multicolumn{6}{l}{ Relationships between Percentage of Students in HFZ and Teachers' Attitudes } \\
\hline & & Overall & & & & \\
& & Attitude & AD & AD-EIF & AD - EUF CD \\
\hline (PACER) \% HFZ & $\mathrm{N}$ & 53 & 53 & 53 & 53 & 53 \\
& Pearson (r) & .176 & .145 & .047 & .245 & .195 \\
& Sig. (1-tailed) & .103 & .150 & .369 & $\mathbf{. 0 3 8}$ & .081 \\
\hline (CU) \% HFZ & $\mathrm{N}$ & 68 & 68 & 68 & 68 & 68 \\
& Pearson (r) & .122 & .085 & -.010 & .214 & .155 \\
& Sig. (1-tailed) & .162 & .245 & .468 & $\mathbf{. 0 4 0}$ & .103 \\
\hline (PU) \% HFZ & $\mathrm{N}$ & 67 & 67 & 67 & 67 & 67 \\
& Pearson (r) & .203 & .158 & .017 & .344 & .238 \\
& Sig. (1-tailed) & $\mathbf{. 0 4 9}$ & .101 & .446 & $\mathbf{. 0 0 2}$ & $\mathbf{. 0 2 6}$ \\
\hline (LSR) \% HFZ & $\mathrm{N}$ & 55 & 55 & 55 & 55 & 55 \\
& Pearson (r) & .118 & .067 & -.034 & .203 & .166 \\
& Sig. (1-tailed) & .196 & .314 & .404 & .069 & .112 \\
\hline (RSR) \% HFZ & N & 53 & 53 & 53 & 53 & 53 \\
& Pearson (r) & .132 & .075 & -.043 & .233 & .185 \\
& Sig. (1-tailed) & .173 & .297 & .379 & $\mathbf{. 0 4 6}$ & .092 \\
\hline
\end{tabular}

Note. $\mathrm{HFZ}=$ Healthy Fitness Zone, $\mathrm{SD}=$ Standard Deviation, $\mathrm{CU}=$ Curl-Up, $\mathrm{PU}=\mathrm{Push}-$ Up, LSR = Left Sit and Reach, RSR = Right Sit and Reach, AD = Affective Domain, EIF = Enjoyment of Implementing Fitness Tests, EUF = Enjoyment of Using Fitness Tests Results, CD = Cognitive Domain.

Additional significant positive relationships were found between the percentage of students in the HFZ on various tests and various components of attitude for girls and boys. For girls, the affective subdomain of teachers' attitude on the enjoyment of using fitness tests results was found to have a significant positive relationship with the percentage of students in the HFZ for the PACER test $[r(52)=.243, p<.05]$, the push-up test $[r(65)=.328, p<.01]$, and the Right Sit and Reach test $[r(49)=.254, p<.05]$. For teachers' overall attitudes toward fitness tests, the only significant relationship found in the correlational analysis was with the percentage of girl students in the HFZ for the 
push-up tests $[r(65)=.217, p<.05]$. Additionally, statistically significant relationships were found between teachers' attitudes toward the usefulness of fitness test results and the percentage of girl students in the HFZ for push-up tests $[r(65)=.241, p<.05]$, Left Sit and Reach tests $[r(51)=.236, p<.05]$, and Right Sit and Reach tests $[r(49)=.292, p<.05]$. A summary of these relationships can be found in Table 10.

Table 10

$\underline{\text { Relationship between Percentage of Female Students in HFZ and Teachers' Attitudes }}$

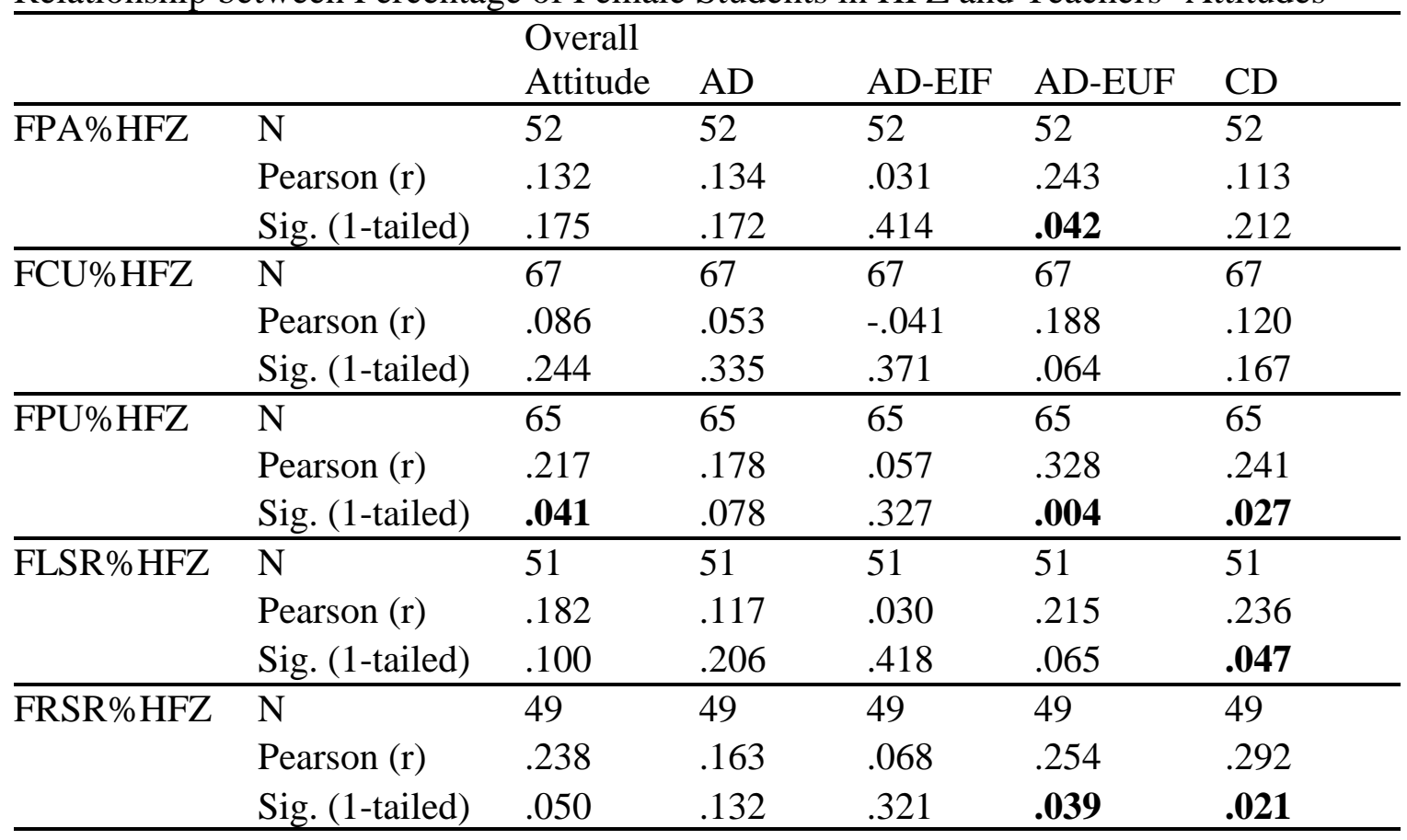

Note. HFZ = Healthy Fitness Zone, $\mathrm{SD}=$ Standard Deviation, $\mathrm{CU}=$ Curl-Up, $\mathrm{PU}=$ PushUp, LSR = Left Sit and Reach, RSR = Right Sit and Reach, AD = Affective Domain, EIF $=$ Enjoyment of Implementing Fitness Tests, EUF $=$ Enjoyment of Using Fitness Tests Results, $\mathrm{CD}=$ Cognitive Domain.

For boys, the affective subdomain of teachers' attitude on the enjoyment of using fitness tests results was found to have a significant positive relationship with the percentage of boy students in the HFZ for the push-up test $[r(64)=.216, p<.05]$. No 
other statistically significant correlations were found between teachers' attitudes and the percentage of boy students in HFZ on various components of the FITNESSGRAM®. A summary of these relationships can be found in Table 11.

Table 11

$\underline{\text { Relationships Between Percentage of Male Students in HFZ and Teachers' Attitudes }}$

\begin{tabular}{lllllll}
\hline & & Overall & & & & \\
& & Attitude & AD & AD-EIF & AD-EUF & CD \\
\hline MPA\%HFZ & $\mathrm{N}$ & 49 & 49 & 49 & 49 & 49 \\
& Pearson (r) & .112 & .088 & .036 & .145 & .127 \\
& Sig. (1-tailed) & .221 & .273 & .403 & .160 & .191 \\
\hline MCU\%HFZ & $\mathrm{N}$ & 65 & 65 & 65 & 65 & 65 \\
& Pearson (r) & .112 & .064 & -.023 & .198 & .162 \\
& Sig. (1-tailed) & .188 & .305 & .428 & .057 & .099 \\
\hline MPU\%HFZ & $\mathrm{N}$ & 64 & 64 & 64 & 64 & 64 \\
& Pearson (r) & .086 & .058 & -.042 & .216 & .113 \\
& Sig. (1-tailed) & .250 & .325 & .370 & .044 & .187 \\
\hline MLSR\%HFZ & $\mathrm{N}$ & 48 & 48 & 48 & 48 & 48 \\
& Pearson (r) & .089 & .008 & -.057 & .119 & .181 \\
& Sig. (1-tailed) & .274 & .478 & .350 & .211 & .109 \\
\hline MRSR\%HFZ & $\mathrm{N}$ & 48 & 48 & 48 & 48 & 48 \\
& Pearson (r) & .110 & .030 & -.021 & .110 & .196 \\
& Sig. (1-tailed) & .229 & .419 & .444 & .229 & .091 \\
\hline
\end{tabular}

Note. HFZ = Healthy Fitness Zone, SD = Standard Deviation, CU = Curl-Up, PU = PushUp, LSR = Left Sit and Reach, RSR = Right Sit and Reach, AD = Affective Domain, EIF $=$ Enjoyment of Implementing Fitness Tests, EUF $=$ Enjoyment of Using Fitness Tests Results, CD = Cognitive Domain.

\section{Relationships: Teacher Variables and Student Performance on Fitness Tests}

In addition to significant relationships between the percentage of students in the HFZ on various tests and various components of attitude, significant relationships were also found between the percentage of students in HFZ on various tests and various teacher demographic variables. For all teachers, teachers' age was found to be 
statistically significant in the correlational analysis with the percentage of male students in the HFZ for the Left Sit and Reach test $[r(48)=.240, p<.05]$ and was found to have a significant positive relationship with the percentage of female students in the HFZ for the Left Sit and Reach test $[r(51)=.353, p<.01]$ and the Right Sit and Reach test $[r(49)$ $=.240, p<.05]$. For all teachers, teachers' age and years of experience were found to be statistically significant in the correlational analysis with the percentage of all students in the HFZ for the sit and reach tests. A summary of the relationship between percentage of students in HFZ and teachers' age and experience can be found in Table 12.

Table 12

Relationship Between Percentage of Students in HFZ and Teachers' Age \& Teachers' Experience

\begin{tabular}{llll}
\hline & & Age & Years Experience \\
\hline (PACER) \% HFZ & $\mathrm{N}$ & 53 & 52 \\
& Pearson (r) & .128 & .100 \\
& Sig. (1-tailed) & .181 & .240 \\
\hline (CU) \% HFZ & $\mathrm{N}$ & 68 & 67 \\
& Pearson (r) & .002 & -.054 \\
& Sig. (1-tailed) & .494 & .332 \\
\hline (PU) \% HFZ & $\mathrm{N}$ & 67 & 66 \\
& Pearson (r) & .091 & .065 \\
& Sig. (1-tailed) & .233 & .302 \\
\hline (LSR) \% HFZ & $\mathrm{N}$ & 55 & 54 \\
& Pearson (r) & .371 & .251 \\
& Sig. (1-tailed) & $\mathbf{. 0 0 3}$ & $\mathbf{. 0 3 3}$ \\
\hline (RSR) \% HFZ & $\mathrm{N}$ & 53 & 52 \\
& Pearson (r) & .307 & .147 \\
& Sig. (1-tailed) & $\mathbf{. 0 1 3}$ & .149 \\
\hline
\end{tabular}

Note. HFZ = Healthy Fitness Zone, CU = Curl-Up, PU = Push-Up, LSR $=$ Left Sit and Reach, RSR $=$ Right Sit and Reach 


\section{Chapter V}

\section{DISCUSSION}

The purpose of this study was to investigate the attitudes of urban middle school physical education teachers toward physical fitness tests. A second purpose of this this study was to examine the relationship between urban middle school teachers' attitudes toward fitness testing and student performance on fitness tests. This chapter will discuss teachers' attitudes toward fitness testing, descriptive data on students' fitness test performance, and the relationship between teachers' attitudes and student performance on fitness tests.

In this study, Ajzen and Fishbein's (1980) TRA and Ajzen's (1989) TPB are found to be essential in the teachers' attitude toward fitness testing and students' performance on fitness tests. The TPB posits that an individual's intention to perform a certain behavior is a strong indicator of how willing the individual is to perform the actual behavior. Intention is the mediator among attitude, subjective norm, and perceived behavior control in determining an individual's behavior. The current study used the TPB to examine teacher attitude toward fitness testing and student performance on fitness tests. The relationships found between teachers' attitudes toward fitness testing and students' performance on fitness tests indicate that teachers' enjoyment of using fitness tests results was significantly associated with the percentage of students in the HFZ, thus supporting the theory that teachers' attitude impacted their intention to use fitness tests results which ultimately influenced student performance on various physical fitness tests. 


\section{Teachers' Attitudes toward Fitness Testing}

Studies on teachers' attitudes toward fitness testing have found that teachers' have neutral to slightly positive attitudes toward fitness testing (Ferguson et al., 2007; Keating et al., 2002; Mercier et al., 2016). These neutral to slightly positive attitudes have been noted to be the result of factors ranging from previous experience (Silverman et al., 2008) to professional development on fitness testing (Keating et al., 2002).

In this study, teachers' overall attitudes toward fitness testing were slightly positive. The attitude mean scores for both female and male teachers also were positive. Male teachers had higher attitude scores than female teachers, although the difference was nonsignificant. These results are similar to the results from previous studies on teachers' attitudes and indicate that fitness testing has the capacity to positively influence the physical education environment when utilized in appropriate ways. More research, however, is needed on teachers' attitudes to better understand how their attitudes are formed toward fitness testing and what factors, if any, can change their attitudes toward fitness testing if any at all.

The attitude mean scores for both female and male teachers in the affective subdomain also was positive. Male teachers had higher attitude scores than female teachers, although, again, the difference was nonsignificant. The enjoyment of implementing fitness tests and using fitness tests results could be impacted by factors outside of the control of the teachers such as professional preparation and administrative support through the limitation of resources, staffing, and allocation of time. Perhaps 
teacher education programs and continuing professional development could incorporate content that is aligned with recommendations in the scholarly literature on the appropriate, effective, and responsible uses of fitness testing (Silverman et al., 2008; Stodden, Sacko, \& Nesbitt, 2017; Wiersma \& Sherman, 2008) in order to influence teachers' affective attitudes, which may then impact various student outcomes in both physical and general education.

Similar to teachers' overall and affective attitudes, the attitude mean scores for both female and male teachers in the cognitive subdomain also were positive. Male teachers had higher attitude scores than female teachers, although, again, the difference was nonsignificant. These results are consistent with previous research on teachers' cognitive attitudes toward fitness testing (Ferguson et al., 2007). Researchers should continue to examine factors that may contribute to teachers' attitude change toward the usefulness of fitness tests results. Research on teachers' health-related fitness knowledge have demonstrated that their knowledge of health-related fitness is low (Castelli \& Williams, 2007). By focusing on developing teachers' health-related knowledge through education and development interventions it may be possible to positively influence changes in their cognitive attitude scores.

The influence of teacher degree levels on teacher attitude toward fitness testing has not been examined in the literature. In this study, teachers with bachelor's degrees had significantly higher attitudes than teachers with a master's degree. PETE programs have been identified in the literature as a context for preservice teachers to learn about health-related fitness and fitness testing (Bulger, Mohr, Carson, \& Wiegand, 2001; 
Harris, 2014; Keating, Chen, Guan, Harrison, \& Dauenhauer, 2009). In 2013, the nation's largest membership organization of health and physical education professional released a guidance document on a comprehensive instructional framework for fitness education in physical education (SHAPE, 2012). As a result of this document and prior research, it is possible that preservice teachers in PETE programs are now learning more on using and implementing fitness tests as part of fitness education learning experiences than in years prior to 2013.

Attitude has been noted to be influenced by previous experience (Keating et al., 2002; Santiago, Disch, \& Morales, 2012; Silverman, 2017). Also, research has found that attitudes are hard to change (Eagly \& Chaiken, 1993; Pajares, 1992). In this study, differences in teachers' attitudes when examined by years teaching experience was not significant. Despite the finding that there were no significant differences in teachers' attitudes by years teaching experience, previous research has established that attitudes are not fixed and, therefore, through multiple ways - pre-service and in-service professional development, professional learning communities, and other strategies - can potentially be changed.

Unlike prior studies (Ferguson et al., 2007; Keating \& Silverman, 2009; Keating et al., 2002), teachers' attitudes by age was significantly different. Notably, Gen X teachers had significantly higher affective attitude scores than baby boomer teachers for the affective subdomain of enjoyment of using fitness tests results. Subramaniam \& Mercier (2017) convey that teachers' attitudes on content play a major role in influencing students' behaviors in physical education and that attitude can be changed. The 
implication from this finding is that the role of fitness testing in schools has changed as a result of continuing professional development and has thus changed the attitude of inservice Gen X teachers. While this interpretation is speculative, research (Castelli \& Williams, 2007; Ferguson et al., 2007) has suggested the importance of continuing professional development, which may have encouraged a greater emphasis on professional development on health-related fitness by professional membership organizations, professional development providers, and school administrators who actively seek opportunities for the staff members through reading professional journals.

\section{Students' Performance on Fitness Tests}

The fitness test with the lowest percentage of students in the HFZ was the PACER test with $44.83 \%$ (s.d.=27.94) in the HFZ. This finding is not surprising, considering authors of prior research in physical education (Garn \& Cothran, 2006; Hopple \& Graham, 2005) have suggested students may not find meaning in activities such as the PACER or other fitness related activities. Studies (Armstrong, 2013; Clark et al., 2015; Marques \& Carreiro da Costa, 2013) on performance among urban youth have also found that aerobic fitness levels decline from elementary school to middle school.

Studies in general education (Coenen, Cornelisz, Groot, Maassen, \& Klaveren, 2018; Dee, 2007) have found that gender interactions between teachers and students do appear to constitute an important environmental influence on outcomes for both girls and boys. No studies in physical education were found to have explored this relationship and 
it was interesting to find in this study that students who had female physical education teachers had a higher percentage in the HFZ, on all fitness test components, than students who had male physical education teachers. This is surprising considering that male teachers had more favorable attitudes toward fitness testing in this study as well as in a prior study on gender differences in teachers' attitudes toward fitness testing (Ferguson et al., 2007). These results may reflect both the portion of female teachers in education. Female teachers represent $77 \%$ of teachers in US public schools (Cox, Parmer, Strizek, \& Thomas, 2016). It could, however, be that factors such as teaching behavior (Flintoff \& Scraton, 2006) and learning environment (Constantinou, Manson, \& Silverman, 2009) have an influence on students' perceptions, attitudes, and behaviors. Additionally, this study found that male students demonstrated higher aerobic fitness levels than female students. This result, however, must be interpreted with caution since adolescents are still developing and have not reached maturity making it difficult to accurately assess whether performance is the result of external factors or naturally occurring development patterns.

Research in general education has found that teacher experience contributes to student performance (Coenen et al., 2018). Studies in physical education have found that teachers' experience influences curriculum (Rovegno, 1993, 1995), health-related fitness content knowledge (Santiago et al., 2012), planning of tasks (Doolittle et al., 1993; Placek et al., 1995), and their attitudes toward fitness tests (Keating et al., 2002). The results from this study support the research that establishes the relationship between experience and performance. Experienced and expert physical educators in this study 
had a higher percentage of their students in the HFZ than novice teachers. The implication for researchers in this finding is to perhaps find ways to involve more experienced teachers in the mentorship of new teachers as it relates to curriculum and instruction in fitness testing. While younger teachers in this study enjoyed implementing fitness tests and using fitness tests results more than older teachers, older teachers had more favorable attitudes on the usefulness of fitness tests. Finding a way to create collaborative learning spaces and communities of practice (Kirk \& Macdonald, 1998; Lave \& Wenger, 1991) to exchange ideas on improving the learning environment could lead to increased attitudes for all teachers and ultimately enhanced teaching and learning.

In addition to the influence of teaching experience on student performance, teachers' age data in this study revealed that Generation X and baby boomers had a higher percentage of students in the HFZ than millennials. While no research to date has established the relation between teachers' age and students performance on fitness tests, it is not surprising that Generation $\mathrm{X}$ and baby boomers in this study had a higher percentage of students in the HFZ based on evidence from the teacher experience data that shows more experienced teachers have a higher percentage of students in the HFZ and that more experienced teachers are likely to fall into the Generation X and baby boomer age categories, though this assumption may not always hold. Generally, with age and experience comes more opportunities for professional collaboration, confidence in teaching, and a greater collection of strategies for teaching health-related fitness. 


\section{Relationships: Teachers' Attitudes and Students' Performance on Fitness Tests}

The significant positive relationship found between teachers' overall attitudes toward fitness testing and the percentage of students in the HFZ for the push-up test supports attitude theory, specifically the TRA and the TPB. Researchers have noted that fitness testing can be used in positive ways that enhance the educational experience (Silverman et al., 2008); thus it is not surprising that teachers in this study who formed favorable beliefs about fitness testing through their experiences positively influenced their students' learning and performance in physical education and on various physical fitness tests.

For teachers' overall attitudes toward fitness tests, the significant relationship found with the percentage of girl students in the HFZ for the push-up test was consistent with that of all students suggesting that teachers may have the capacity to positively impact health-related fitness outcomes among urban female adolescents. This is important in that girls overall are less physically active than boys (Chung, Skinner, Steiner, \& Perrin, 2012). While some research has noted that genetics, maturation and physiology are important factors in the differences, other research (Basch, 2011) finds that opportunities, or lack thereof, for physical activity participation are also factors that are important. Regardless, the finding in this study that a relationship exists between teachers' attitudes toward fitness testing and the percentage of female students in the HFZ for the push-up test is meaningful given that attitudes play a major role in curriculum, teaching, and student learning. 
The significant positive relationships found between teachers' affective attitudes and the percentage of students in the HFZ for the PACER test, curl-up test, push-up test, and sit-and-reach test further support attitude theory and provide valuable insight into the role that teachers' affective attitudes may play in improving health outcomes among adolescents. Further, it supports previous scholarship regarding teachers' attitudes on content and its role in influencing students' behaviors in physical education (Subramaniam \& Mercier, 2017). When combined with the evidence that has established a positive association between cardiorespiratory endurance and health in youth (Stodden et al., 2017), the results are especially useful. When teachers' enjoyment of implementing fitness tests and using fitness results are favorable, not only are students more likely to perform better but they are also potentially more likely to adopt healthy lifestyles that can lead to favorable health outcomes. This is especially important given the decline in youth physical activity levels along with other negative health outcomes, primarily the increase in childhood obesity.

The most prevalent enjoyment factor in this study was the affective subdomain of teachers' attitude on the enjoyment of using fitness tests results. The significant positive relationships found between teachers' attitude on the enjoyment of using fitness tests results and the percentage of students in the HFZ for the PACER test, curl-up test, pushup test, and sit-and-reach test strongly suggests that teachers' enjoyment of using fitness tests results play a major role in improving health-related performance outcomes among adolescents. 
For girls, the affective subdomain of teachers' attitude on the enjoyment of using fitness tests results was found to have a significant positive relationship with the percentage of students in the HFZ for the PACER test, the push-up test, and the Right Sit and Reach test. While Alfrey and Gard (2017, p. 9) suggest that "shaming has emerged as both an intended and unintended consequence of fitness testing in physical education," this study's results advance an alternative that suggests girls are not shamed but rather valued. While the results show how attitude can influence behavior, more importantly the results support the recent literature on positive pedagogical approaches to fitness testing (Silverman et al., 2008; SHAPE, 2012) that indicate fitness testing can further educational goals, improve fitness knowledge and performance, and increase physical activity levels among youth.

Perhaps the enjoyment of developing competence in their students by teaching them how to use fitness tests results as a self-assessment (Silverman et al., 2008; Wiersma \& Sherman, 2008) contributed to students performance on the various fitness tests. This collaborative approach, in addition to other pedagogical approaches to fitness testing, of encouraging student learning and performance rather than using results to grade student performance in physical education (McKenzie, 2003), one among many of inappropriate uses of fitness testing (McKenzie \& Lounsbery, 2013), demonstrates the effectiveness of teachers' enjoyment of using fitness tests results to improve student physical activity and health-related fitness. 


\section{Summary}

The results from this study reveal that teachers' attitudes are related to student performance on fitness tests. While the high standard deviations require the data to be interpreted with caution, the data also compels the physical education field and its' researchers to further study teachers' attitudes toward fitness testing and other factors potentially contributing to student learning and performance in physical education, specifically student performance on physical fitness tests designed to ascertain whether students are maintaining healthy levels of physical activity and fitness.

As the debate on the value of physical fitness testing in schools continues, this study highlights the need for more research on fitness testing and the many factors that potentially influence or associate with fitness testing in physical education. Without additional evidence to support or discourage fitness testing in school, the debate over its importance and value in physical education will continue to distract from the development of solutions to bring about positive change in student educational outcomes, to include health-related fitness knowledge and behavior outcomes. 


\section{REFERENCES}

Ajzen, I. (1989). Attitude structure and behavior. In A.R. Pratkanis, S.J. Breckler, \& A.G. Greenwald (Eds.), Attitude structure and function (pp.241-274). Hillsdale, NJ: Lawrence Erlbaum.

Ajzen, I. (1991). The theory of planned behavior. Organizational Behavior and Human Decision Processes, 50, 179-211.

Ajzen, I. (2001). Nature and operations of attitudes. Annual Review of Psychology, 52, 27-58.

Ajzen, I. (2012). The theory of planned behavior. In P. A. M. Lange, A. W. Kruglanski, $\&$ E. T. Higgins (Eds.), Handbook of theories of social psychology (Vol. 1, pp. 438-459). London: Sage.

Ajzen, I., \& Fishbein, M. (1977). Attitude-behavior relations: A theoretical analysis and review of empirical research. Psychological Bulletin, 84, 888-918.

Ajzen, I., \& Fishbein, M. (1980). Understanding attitudes and predicting behavior. Englewood Cliffs, NJ: Prentice Hall.

Alfrey, L., \& Gard, M. (2017). Figuring out the prevalence of fitness testing in physical education. European Physical Education Review, 1-16.

American Association for Health, Physical Education, and Recreation. (1958). AAHPER youth fitness test manual. Washington, DC: Author.

American Association for Health, Physical Education, and Recreation. (1965). AAHPER youth fitness test manual, revised edition. Washington, DC: Author.

American Alliance for Health, Physical Education, Recreation and Dance. (1976). AAHPERD youth fitness test manual, revised 1976 edition. Reston, VA: Author.

American Alliance for Health, Physical Education, Recreation and Dance. (1980). Health related physical fitness test manual. Reston, VA: Author.

American Alliance for Health, Physical Education, Recreation and Dance. (1984). Technical manual: Health related physical fitness. Reston, VA: Author. 
Apple, M.W. (1982). Education and power. Boston, MA: ARK.

Armstrong, N. (2013). Aerobic fitness and physical activity in children. Pediatric Exercise Science, 25, 548-60.

Bai, H., \& Ertmer, P.A. (2008). Teacher educators' beliefs and technology uses as predictors of preservice teachers beliefs and technology attitudes. Journal of Technology and Teacher Education, 16, 93-112.

Bandura, A. (1986). Social foundations of thought and action: A social cognitive theory. Englewood Cliffs, NJ: Prentice Hall.

Basch, C. E. (2011). Physical activity and the achievement gap among urban minority youth. The Journal of School Health, 81, 626-643.

Baumgartner, T. A., \& Gaunt, S. J. (2005). Construct related validity for the Baumgartner Modified Pull-Up Test. Measurement in Physical Education and Exercise Science, 9, 51-60.

Bernstein, E., Phillips, S.R., \& Silverman, S. (2011). Attitudes and perceptions of middle school students toward competitive activities in physical education. Journal of Teaching in Physical Education, 30, 69-83.

Biddle, S. J., Gorely, T., \& Stensel, D. J. (2004). Health-enhancing physical activity and sedentary behavior in children and adolescents. Journal of Sports Sciences, 22, 679-701.

Brace, D. K. (1947). Studies in motor learning of gross bodily motor skills. Research Quarterly, 17, 242-253.

Brattesani, K. A., Weinstein, R. S., \& Marshall, H. H. (1984). Student perceptions of differential teacher treatment as moderators of teacher expectation effects. Journal of Educational Psychology, 76, 236-247.

Brecker, S.J. (1984). Empirical validation of affect, behavior and cognition as distinct components of attitude. Journal of Personality and Social Psychology, 47, 11911205 .

Brickhouse, N.W. (1990). Teachers' beliefs about the nature of science and their relationships to classroom practice. Journal of Teacher Education, 41, 53-62.

Brophy, J.E, \& Good, T. L. (1986). Teaching behavior and student achievement. In M.C. Wittrock (Ed.), Handbook of research on teaching (3d ed., pp. 376-391). New York, NY: Macmillan. 
Brown, C. A., \& Cooney, T. J. (1982). Research on teacher education: A philosophical orientation. Journal of Research and Development in Education, 15(4), 13-18.

Brown, S., \& Melear, C. (2006). Investigation of secondary science teachers' beliefs and practices after authentic inquiry-based experiences. Journal of Research in Science Teaching, 43, 938-962.

Bulger, S.M., Mohr, D.J., Carson, L.M., \& Wiegand, R.L. (2001). Infusing health-related physical fitness in physical education teacher education. Quest, 53, 403-417.

Calderhead, J., \& Robson, M. (1991). Images of teaching: Student teachers' early conceptions of classroom practice. Teaching \& Teacher Education, 7, 1-8.

Cale, L., Harris, J., \& Chen, M. (2007). More than 10 years after "The Horse is Dead...": Surely it must be time to "Dismount"?! Pediatric Exercise Science, 19, 115-131.

Castelli, D., \& Rink, J. E. (2003). A comparison of high and low performing secondary physical education program. Journal of Teaching in Physical Education, 22, 512532.

Castelli, D., \& Williams, L. (2007). Health-related fitness and physical education teachers' content knowledge. Journal of Teaching in Physical Education, 26, 3 19.

Centeio, E. F., \& Keating, X. D. (2011). How phat is your fitness knowledge? Research Quarterly for Exercise and Sport, 82, A3.

Centers for Disease Control and Prevention (2009). School connectedness: Strategies for increasing protective factors among youth. Atlanta, GA: Centers for Disease Control and Prevention.

Centers for Disease Control and Prevention (2010). The association between school based physical activity, including physical education, and academic achievement. Atlanta, GA: U.S. Department of Health and Human Services, CDC.

Chen, A. (1998). Meaningfulness in physical education: A description of high school students' conceptions. Journal of Teaching in Physical Education, 17, 270-306.

Chen, A., \& Ennis, C.D. (1996). Teaching value-laden curricula in physical education. Journal of Teaching in Physical Education, 15, 338-354.

Chung, A. E., Skinner, A. C., Steiner, M. J., \& Perrin, E. M. (2012). Physical activity and BMI in a nationally representative sample of children and adolescents. Clinical Pediatrics, 51, 122-129. 
Coenen, J., Cornelisz, I., Groot, W., Maassen van den Brink, H., \& Klaveren, C. (2018). Teacher characteristics and their effects on student test scores: A systematic review. Journal of Economic Surveys, 32, 848-877.

Conkle, T. (1997). Inservice programs - What do physical educators want? Journal of Physical Education, Recreation, and Dance, 68(8), 50-55.

Constantinou, P., Manson, M., \& Silverman, S. (2009). Female students' perceptions about gender-role stereotypes and their influence on attitude toward physical education. The Physical Educator, 66, 85-97.

Corbin, C. B. (1981). First things first but don't stop there. Journal of Physical Education, Recreation and Dance, 52(1), 36-38.

Corbin, C.B. (2002). Physical activity for everyone: What every physical educator should know about promoting lifelong physical activity. Journal of Teaching Physical Education, 21, 128-144.

Corbin, C.B., \& Pangrazi, R.P. (1992). Are American children and youth fit? Research Quarterly for Exercise and Sport, 63, 96-106.

Corbin, C. B., Pangrazi, R. P., \& Welk, G. J. (1995). A response to "The Horse is Dead; Let's Dismount." Pediatric Exercise Science, 7, 347-351.

Corbin, C.B., Welk, G., J., Richardson, C., Vowell, C., Lambdin, D., \& Wikgren, S. (2014). Youth physical fitness: Ten key concepts. Journal of Physical Education, Recreation and Dance, 85(2), 24-31.

Cothran, D.J., \& Ennis, C.D. (1997). Students' and teachers' perceptions of conflict and power. Teaching and Teacher Education, 13, 541-553.

Cox, S., Parmer, R., Strizek, G., \& Thomas, T. (2016). Documentation for the 2011-12 Schools and Staffing Survey (NCES 2016-817). Washington, DC: National Center for Education Statistics.

Crawley, F. E. (1990). Intentions of science teachers to use investigative teaching methods: A test of the Theory of Planned Behavior. Journal of Research in Science Teaching, 27, 685-697.

Cronin-Jones, L. L. (1991). Science teacher beliefs and their influence on curriculum implementation: Two case studies. Journal of Research in Science Teaching, 28, 235-250. 
Darling-Hammond, L., Furger, R., Shields, P., \& Sutcher, L. (2016). Addressing California's emerging teacher shortage: An analysis of sources and solutions. Palo Alto, CA: Learning Policy Institute.

Dee, T. (2007). Teachers and the gender gaps in student achievement. Journal of Human Resources, 42, 528-554.

Dewey, J. (1916). Democracy and education. New York, NY: Macmillan.

Doolittle, S., Dodds, P., \& Placek, J. (1993). Persistence of beliefs about teaching during formal training of preservice teachers. Journal of Teaching in Physical Education, 12, 355-365.

Doyle, W. (1978). Are students behaving worse than they used to behave? Journal of Research and Development in Education, 2(4), 3-16.

Doyle, W. (1979). Classroom tasks and students' abilities. In P.L. Peterson \& H.J. Walberg (Eds.), Research on teaching: Concepts, findings and implications (pp. 183-209). Berkeley, CA: McCutchan.

Doyle, W. (1983). Academic work. Review of Educational Research, 53, 159-199.

Eagly, A. H., \& Chaiken, S. (1993). The psychology of attitudes. Orlando, FL: Harcourt Brace Jovanovich.

Eisner, E.W., \& Vallance, E. (Eds.) (1974). Conflicting conceptions of curriculum. Berkeley, CA: McCutchan.

Ennis, C. D. (1992). Curriculum theory as practices: Case studies of operationalized value orientations. Journal of Teaching in Physical Education, 11, 358-375.

Ennis, C. D. (1994a). Knowledge and beliefs underlying curricular expertise. Quest, 46, 164-175.

Ennis, C. D. (1994b). Urban secondary teachers' value orientations: Delineating curricular goals for social responsibility. Journal of Teaching in Physical Education, 13, 163-179.

Ennis, C.D. (1995). Teachers' responses to noncompliant students: The realities and consequences of a negotiated curriculum. Teaching and Teacher Education, 11, $59-78$. 
Ennis, C. D. (1996). A model describing the influence of values and context on student learning. In S. J. Silverman, \& C. D. Ennis (Eds.). Student Learning in Physical Education: Applying Research to Enhance Instruction (pp. 127-147). Champaign, IL: Human Kinetics.

Ennis, C.D. (1998). Shared expectations: Creating a joint vision for urban schools. In J. Brophy (Ed.). Advances in research on teaching, Vol. 7, (pp. 151-182). New York, NY: JAI Press.

Ennis, C. D., \& Chen A. (1993). Domain specification and content: Representative of the Revised Value Orientation Inventory. Research Quarterly for Exercise and Sport, 64, 436-446.

Ennis, C. D., \& Chen, A. (1995). Teachers' value orientation in urban and rural school settings. Research Quarterly for Exercise and Sport, 66, 41-50.

Ennis, C., \& Chen, A. (1996). Teaching value-laden curricula in physical education. Journal of Teaching in Physical Education, 15, 338-354.

Ennis, C. D., Chen, A., \& Ross, J. (1992). Educational value orientations as a theoretical framework for experienced urban teachers' curricular decision making. Journal of Research and Development in Education, 25, 156-163.

Ennis, C. D., Cothran, D. J., Davison, K. S., Loftus, S. J., Owens, L., Swanson, L., \& Hopsicker, P. (1997). Implementing curriculum within a context of fear and engagement. Journal of Teaching in Physical Education, 17, 52-71.

Ennis, C. D., \& Zhu, W. (1991). Value orientations: A description of teachers' goals for students. Research Quarterly for Exercise and Sport, 62, 33-40.

Ernst, M. P., Corbin, C. B., Beighle, A., \& Pangrazi, R. P. (2006). Appropriate and inappropriate uses of FitnessGram ${ }^{\circledR}$ : A Commentary. Journal of Physical Activity and Health, 3(supplement 2), S90-S100.

Fairclough S.J., Beighle A., Erwin, H., \& Ridgers, N.D. (2012). School day segmented physical activity patterns of high and low active children. BMC Public Health, 12, 406.

Fairclough, S.J, \& Stratton, G. (2005). "Physical education makes you fit and healthy," Physical education contribution to young people's physical activity levels. Health Education Research, 20, 14-23. 
Fairclough S.J, \& Stratton, G. (2006). A review of physical activity levels during elementary school physical education. Journal of Teaching in Physical Education, $25,239-257$.

Fakhouri, T.H.I, Hughes, J. P., Burt, V. L., Song, M., Fulton, J. E., \& Ogden, C. L. (2014). Physical activity in U.S. youth aged 12-15 years, 2012. Centers for Disease Control and Prevention.

Ferguson, R. H., Keating, X. D., Bridges, D. M., Guan, J., \& Chen, L. (2007). California secondary school physical education teachers' attitudes toward the mandated use of the FitnessGram®. Journal of Teaching in Physical Education, 26, 159-173.

Fishbein, M., \& Ajzen, I. (1975). Belief, attitude, intention, and behavior: An introduction to theory and research. Reading, MA: Addison-Wesley.

Fishbein, M., \& Ajzen, I. (2010). Predicting and changing behavior: The reasoned action approach. New York, NY: Psychology Press.

FitnessGram ${ }^{\circledR}$ (2007). FITNESSGRAM®® Healthy Fitness Zones. Dallas, TX: The Cooper Institute.

Flintoff, A., \& Scraton, S. (2006). Girls and physical education. In D. Kirk, D. Macdonald, \& M. O'Sullivan (Eds.), Handbook of Physical Education (pp. 767783). London, UK: Sage.

Franks, B.D., Morrow, J.R., Jr., \& Plowman, S.A. (1988). Youth fitness testing: Validation, planning, and politics. Quest, 40, 187-199.

Fraser, B. J., Walberg, H. J., Welch, W. W., \& Hattie, J. A. (1987). Syntheses of educational productivity research. International Journal of Educational Research, $11,145-252$.

Freedson, P.S., Cureton, K.J., \& Heath, G.W. (2000). Status of field-based fitness testing in children and youth. Preventive Medicine, 31, S77-S85.

French, K., Rink, J., Rikard, L., Mays, A., Lynn, S., \& Werner, P. (1991). The effects of practice progressions on learning volleyball skills. Journal of Teaching in Physical Education, 10, 261-274.

French, K.E., Rink, J.E., \& Werner, P.H. (1990). Effects of contextual interference on retention of three volleyball skills. Perceptual and Motor Skills, 71, 179-186.

Garn, A. C., \& Cothran, D. J. (2006). The Fun Factor in Physical Education. Journal of Teaching in Physical Education, 25, 281-297. 
Good, S., \& Magill, R.A. (1986). The contextual interference effects in learning three badminton serves. Research Quarterly for Exercise and Sport, 57, 308-314.

Good, T.L. (1987). Two decades of research on teacher expectations: Findings and future directions. Journal of Teacher Education, 38, 32-47.

Good, T., Biddle, B., \& Brophy, J. (1975). Teachers make a difference. New York, NY: Holt, Rinehart, and Winston.

Goodman, J. (1988). Constructing a practical philosophy of teaching: A study of preservice teachers' professional perspectives. Teaching and Teacher Education, $4,121-137$.

Gordon-Larsen P., McMurray R.G., \& Popkin B.M. (2000). Determinants of adolescent physical activity and inactivity patterns. Pediatrics, 105(6), e83.

Haney, J. J., Czerniak, C., \& Lumpe, A. T. (1996). Teachers' beliefs and intentions regarding the implementation of science education reform strands. Journal of Research in Science Teaching, 33, 971-993.

Harris, J. (2014). Physical education teacher education students' knowledge, perceptions and experiences of promoting healthy, active lifestyles in secondary schools. Physical Education and Sport Pedagogy, 19, 466-480.

Harris, J., \& Cale, L. (2006). A review of children's fitness testing. European Physical Education Review, 12, 201-225.

Hartman, J.G., \& Looney, M.A. (2003). Norm-referenced and criterion-referenced reliability and validity of the back-saver sit-and-reach. Measurement in Physical Education and Exercise Science, 7, 71-87.

Hastie, P.A., \& Saunders, J.E. (1991). The effects of class size and equipment availability on student lesson involvement in primary school physical education. Journal of Experimental Education, 59, 212-224.

Hillman, C.H., Pontifex, M.B., Motl, M.B., O'Leary, K.C., Johnson, C.R., Scudder, M.R.,...Castelli, D. (2012). From ERP's to academics. Developmental Cognitive Neuroscience, 2, S90-S98.

Hollon, R. E., \& Anderson, C. W. (1987). Teachers' beliefs about students learning processes in science: Self-reinforcing belief systems. Paper presented at the meeting of the American Educational Research Association, Washington, DC. 
Hopple, C, \& Graham, G. (1995). What children think, feel, and know about physical fitness testing. Journal of Teaching in Physical Education, 14, 408-417.

Howie, E. K., \& Pate, R. P. (2012). Physical activity and academic achievement in children: A historical perspective. Journal of Sport and Health Science, 1, 160169.

Huba, M.E., \& Freed, J.E. (2000). Learner-centered assessment on college campuses: Shifting the focus from teaching to learning. Needham Heights, MA: Allyn \& Bacon.

Ihmels, M., Welk, G.J., McClain, J.J., \& Schaben, J. (2006). The reliability and convergent validity of field tests of body composition in young adolescents. Journal of Physical Activity \& Health, 3(s2), 67-77.

Institute of Medicine. (2012). Fitness measures and health outcomes in youth. Washington, DC: The National Academies Press.

Institute of Medicine. (2013). Educating the student body: Taking physical activity and physical education to school. Washington, DC: The National Academies Press.

Jewett, A. E., Bain, L. L., \& Ennis, C. D. (1995). The curriculum process in physical education (2nd ed.). Madison, WI: Brown \& Benchmark.

Jones, M. G., \& Carter, G. (2007). Science teacher attitudes and beliefs. In S. K. Abell \& N. G. Lederman (Eds.), Handbook of research on science education (pp. 10671104). Mahwah, NJ: Erlbaum.

Keating, X.D. (2003). The current often implemented fitness tests in physical education programs: Problems and future directions. Quest, 55, 141-160.

Keating, X.D., Chen, L., Guan, J., Harrison, L., \& Dauenhauer, B. (2009). Urban minority ninth-grade students' health-related fitness knowledge. Research Quarterly for Exercise and Sport, 80, 747-755.

Keating, X. D., Ferguson, R. H., Chen, L., \& Bridges, D. M. (2008). Physical education teacher attitudes toward fitness tests scale: Cross-revalidation and modification. Measurement in Physical Education and Exercise Science, 12, 72-87.

Keating, X.D., \& Silverman, S. (2004a). Physical education teacher attitudes toward fitness test scale: Development and validation. Journal of Teaching in Physical Education, 23, 143-161. 
Keating, X.D., \& Silverman, S. (2004b). Teachers' use of fitness tests in school-based physical education programs. Measurement in Physical Education and Exercise Science, 8, 145-165.

Keating, X. D., \& Silverman, S. (2009). Determinants of teacher implementation of youth fitness tests in school-based physical education programs. Physical Education and Sport Pedagogy, 14, 209-225.

Keating, X.D., Silverman, S., \& Kulinna, P.H. (2002). Preservice physical education teacher attitudes toward fitness tests and the factors influencing their attitudes. Journal of Teaching in Physical Education, 21, 193-207.

Kirk, D., \& Macdonald, D. (1998). Situated learning in physical education. Journal of Teaching in Physical Education, 17, 376-387.

Kraus, H., \& Hirschland, R.P. (1954). Minimum muscular fitness tests in school children. Research Quarterly, 25, 178-188.

Kulinna, P. H., \& Silverman, S. (2000). Teachers' attitudes toward teaching physical activity and fitness. Research Quarterly for Exercise and Sport, 71, 80-84.

Kwak, E. (1993). The initial effects of various task presentation conditions on student's performance in the lacrosse throw. (Unpublished doctoral dissertation). The University of South Carolina, Columbia, SC.

Landwer, J.E. (2009). "AAHPERD 1986-2009: A Retrospective: although the Alliance has evolved throughout the years, AAHPERD's mission remains the same." The Journal of Physical Education, Recreation \& Dance, 80(9), 48-50.

Lave, J., \& Wenger, E. (1991). Situated learning: Legitimate peripheral participation. Cambridge: Cambridge University Press.

Lee, T.D., Swinnen, S.P., \& Serrien, D.J. (1994). Cognitive effort and motor learning. Quest, 46, 328-344.

Lobelo F., Pate R., Dowda M., Liese A., \& Ruiz J.R. (2009). Validity of cardiorespiratory fitness criterion-referenced standards for adolescents. Medicine \& Science in Sports \& Exercise, 41, 1222-1229.

Lubans, D.R., Morgan, P., Callister, R., Plotnikoff, R.C., Eather, N., Riley, N., \& Smith, C.J. (2011). Test-retest reliability of a battery of field-based health-related fitness measures for adolescents. Journal of Sports Sciences, 29, 685-693. 
Lumpe A.T., Czerniak C.M., Haney J., \& Beltyukova, S. (2012). Beliefs about teaching science: The relationship between elementary teachers' participation in professional development and student achievement. International Journal of Science Education, 34, 153-166.

Lumpe, A. T., Haney, J. J., \& Czerniak, C. M. (1998). Teachers' beliefs about science, technology, society reforms. Journal of Science Teacher Education, 9, 1-24.

Lund, J., \& Shanklin, J. (2011). The impact of accountability on student response rate in a secondary physical education badminton unit. The Physical Educator, 68, 210220.

Magill, R. A. (2001). Motor learning: Concepts and applications (6th ed.). Madison, WI: Brown \& Benchmark.

Mansour, N. (2009). Science teachers' beliefs and practices: Issues, implications and research agenda. International Journal of Environmental \& Science Education, 4, $25-48$.

Marques, A., \& Carreiro da Costa, F. (2013). Levels of physical activity of urban adolescents according to age and gender. International Journal of Sports Science, $3,23-27$.

Martin, J., \& McCaughtry, N. (2008). Using social cognitive theory to predict physical activity in inner-city African American school children. Journal of Sport and Exercise Psychology, 30, 378-391.

Martin, J., Oliver, K., \& McCaughtry, N. (2007). The theory of planned behavior: Predicting physical activity in Mexican American children. Journal of Sport \& Exercise Psychology, 29, 225-238.

Maslow, A. H. (1979). The journals of A. H. Maslow (R. J. Lowry, Ed.; Vols. 1-2). Monterey, CA: Brooks/Cole.

McCaughtry, N., Barnard, S., Martin, J., Shen, B. \& Hodges-Kulinna, P. (2006).

Teachers' perspectives on the challenges of teaching physical education in urban schools: The student emotional filter. Research Quarterly for Exercise and Sport, 77, 486-497.

McConnell, J. (1977). Relationships between selected teacher behaviors and attitudes/achievements of algebra classes. Paper presented at the annual meeting of the American Educational Research Association. 
McCloy, C. H., \& Young, D. Y. (1954). Tests and measurements in health and physical education (3rd ed.). New York, NY: Appleton.

McGuire, W.J. (1969). The nature of attitudes and attitude change. In G. Lindsey \& E. Aronson (Eds.), Handbook of social psychology ( $2^{\text {nd }}$ ed., pp. $\left.136-314\right)$. Reading, MA: Addison-Wesley.

McKenzie, T.L. (2003). Health-related physical education: Physical activity, fitness, and wellness. In S.J. Silverman \& C.D. Ennis (Eds.), Student learning in physical education: Applying research to enhance instruction ( $2^{\text {nd }}$ ed., pp. 207-226). Champaign, IL: Human Kinetics.

McKenzie, T. L., \& Lounsbery, M. (2013). Physical education teacher effectiveness in a public health context. Research Quarterly for Exercise and Sport, 84, 419-430.

McKenzie, T. L., \& Sallis, J. F. (1996). Physical activity, fitness, and health-related physical education. In S.J. Silverman, \& C.D. Ennis (Eds.), Student Learning in Physical Education: Applying Research to Enhance Instruction, (pp. 223-246). Champaign, IL: Human Kinetics.

McNeil, J.D. (1990). Curriculum: A comprehensive introduction. Boston, MA: Little, Brown.

Mercier, K., Phillips, S., \& Silverman, S. (2016). High school teachers' use of and attitudes toward fitness tests. The High School Journal, 99, 179-190.

Mercier, K., \& Silverman, S. (2014). Validation of an instrument to measure high school students' attitudes toward fitness testing. Research Quarterly for Exercise and Sport, 85, 81-89.

Metzler, M. (1989). A review of research on time in sport pedagogy. Journal of Teaching in Physical Education, 8, 87-103.

Morrow, J. R., Jr., \& Ede, A. (2009). Statewide physical fitness testing: A big waist or a big waste? Research Quarterly for Exercise and Sport, 80, 696-701.

Morrow, J.R., Jr., Martin, S.B., \& Jackson, A.W. (2010). Reliability and validity of the FITNESSGRAM®: Quality of teacher-collected health-related fitness surveillance data. Research Quarterly for Exercise and Sport, 81, s24-s30.

Morrow, J.R., Jr., Zhu, W., Franks, B.D., Meredith, M.D., \& Spain, C. (2009). 19582008: 50 years of youth fitness tests in the United States. Research Quarterly for Exercise and Sport, 80, 1-11. 
Melendez, J.S., \& Silverman, S. (2005). The relationship between teachers' attitude toward fitness testing and student performance on the Connecticut physical fitness assessment. Poster presentation at the annual meeting of the American Alliance for Health, Physical Education, Recreation, and Dance, Chicago, IL.

Mitchell, M., Castelli, D., \& Strainer, S. (2003). Student performance data, school attributes, and relationships. Journal of Teaching in Physical Education, 22, 494511.

Murnane, R. J., \& Phillips, B. R. (1981). What do effective teachers of inner-city children have in common? Social Science Research, 10, 83-100.

National Association for Sport and Physical Education (2003). What constitutes a quality physical education program [Position statement]. Reston, VA: Author.

National Association for Sport and Physical Education (2004). Moving to the Future: National Standards for Physical Education (2 ${ }^{\text {nd }}$ ed.). Reston, VA: Author.

National Association for Sport and Physical Education (2012). Instructional framework for fitness education in physical education. Reston, VA: Author.

Nespor, J. (1987). The role of teacher beliefs in the practice of teaching. Journal of Curriculum Studies, 19, 317-328.

Ogden, C.L., Carroll, M.D., Kit, B.K., \& Flegal, K.M. (2014). Prevalence of childhood and adult obesity in the United States, 2011-2012. The Journal of the American Medical Association, 311, 806-814.

Ortega, F. B., Labayen, I., Ruiz, J. R., Kurvinen, E., Loit, H. M., Harro, J. \& Sjöström, M. (2011). Improvements in fitness reduce the risk of becoming overweight across puberty. Medicine and Science in Sports and Exercise, 43, 1891-1897.

Ortega, F.B., Ruiz, R.J., Castillo, M.J., \& Sjostrom, M., (2008). Pediatric review: Physical fitness in childhood and adolescence: A powerful marker of health. International Journal of Obesity, 32, 1-11.

Pajares, F. M. (1992). Teachers' beliefs and educational research: Cleaning up a messy construct. Review of Educational Research, 62, 307-332.

Papert, S. (1980). Mindstorms: Children, computers, and powerful ideas. New York, NY: Basic Books. 
Pate, R.R. (1989). The case for large-scale physical fitness testing in American youth. Pediatric Exercise Science, 1, 295-302.

Pate, R.R. (1991). Health-related measures of children's physical fitness. The Journal of School Health, 61, 231-233.

Pate, R., Burgess, M., Woods, J., Ross, J., \& Baumgartner, T. (1993). Validity of field tests of upper body muscular strength. Research Quarterly for Exercise and Sport, 64, 17-24.

Pate, R.R., Welk, G.J., \& McIver, K.L. (2013). Large-scale youth physical fitness testing in the United States: A 25-year retrospective review. Pediatric Exercise Science, $25,515-523$.

Placek, J. H., \& Dodds, P. (1988). A critical incident study of preservice teachers' beliefs about teaching success and nonsuccess. Research Quarterly for Exercise and Sport, 59, 351-358.

Placek, J. H., Dodds, P., Doolittle, S. A., Portman, P. A., Ratliffe, T. A., \& Pinkham, K. M. (1995). Teaching recruits' physical education backgrounds and beliefs about the purposes for their subject matter. Journal of Teaching in Physical Education, $14,246-261$.

Placek, J.H., Griffin, L.L., Dodds, P., Raymond, C., Tremino, F., \& James, A. (2001). Middle school students' conceptions of fitness: The long road to a healthy lifestyle. Journal of Teaching Physical Education, 20, 314-323.

Plowman, S. A., Sterling, C.L., Corbin, C.B., Meredith, M.D., Welk, G.J., \& Morrow, J., Jr. (2006). The history of FitnessGram ${ }^{\circledR}$. Journal of Physical Activity \& Health, 3 , S5-S20.

Racette, S., Dill, T., White, M., Castillo, J., Uhrich, M., Inman, C., \& Clark, B. (2015). Influence of physical education on moderate-to-vigorous physical activity of urban public school children in St. Louis, Missouri, 2011-2014. Preventing Chronic Disease, 12(E31), 1-4.

Rikard, G.L. (1992). The relationship of teachers' task refinement and feedback to students' practice success. Journal of Teaching in Physical Education, 11, 349357.

Rikard, L., \& Banville, D. (2006). High school student attitudes about physical education. Sport, Education, and Society, 11, 385-400.

Rink, J. (1994). Task presentation in pedagogy. Quest, 46, 270-280. 
Rokeach, M. (1968). Beliefs, attitudes, and values: A theory of organization and change. San Francisco, CA: Jossey-Bass.

Rosenberg, M. J., \& Hovland, C. I. (1960). Cognitive, affective, and behavioral components of attitudes. In C. I. Hovland \& M.J. Rosenberg (Eds.), Attitude organization and change (pp. 1-14). New Haven, CT: Yale University Press.

Rosenshine, B. (1971). New directions for research on teaching. In U.S. Office of Education, Bureau of Educational Personnel Development How teachers make a difference (pp. 66-96). Washington, DC: U. S. Government Printing Office.

Rosenshine, B. (1983). Teaching functions in instructional programs. Elementary School Journal, 83, 335-351.

Rosenshine, B., \& Furst, N. (1973). Chapter 3: Research on teacher performance criteria. In B. Othanel Smith (Ed.), Research in teacher education - A symposium (pp. 3772). Englewood Cliffs, NJ: Prentice-Hall.

Rovegno, I. (1993). The development of curricular knowledge: A case of problematic pedagogical content knowledge during advanced knowledge acquisition. Research Quarterly for Exercise and Sport, 64, 56-68.

Rovegno, I. (1995). Theoretical perspectives on knowledge and learning and a student teacher's pedagogical content knowledge of dividing and sequencing subject matter. Journal of Teaching in Physical Education, 14, 284-304.

Safrit, M. J. (1990). The validity and reliability of fitness tests for children: A review. Pediatric Exercise Science, 2, 9-28.

Safrit, M. J., \& Wood, T.M. (1986). The health-related physical fitness test: A tri-state survey of users and non-users. Research Quarterly for Exercise and Sport, 57, 2732.

Safrit, M. J., \& Wood, T. M. (1987). The test battery reliability of the health- related physical fitness test. Research Quarterly for Exercise and Sport, 58, 160-167.

Santiago, J. A., Disch, J. G., \& Morales, J. (2012). Elementary physical education teachers' content knowledge pf physical activity and health-related fitness. The Physical Educator, 69, 395-412.

Sherman, T., \& Barfield, J. P. (2006). Equivalence reliability among FITNESSGRAM@® upper-body tests of muscular strength and endurance. Measurement in Physical Education and Exercise Science, 10, 241-254. 
Silverman, S. (1985). Relationship of engagement and practice trials to student achievement. Journal of Teaching in Physical Education, 5, 13-21.

Silverman, S. (1990). Linear and curvilinear relationships between student practice and achievement in physical education. Teaching and Teacher Education, 6, 305-314.

Silverman, S. (1993). Student characteristics, practice and achievement in physical education. Journal of Educational Research, 87, 54-61.

Silverman, S. (2005). Low-skilled children in physical education: A model of factors that that impact their experiences and learning. In F. Carrerio da Costa, M. Cloes, \& M. Gonález (Eds.), The art and science of teaching in physical education and sport (pp. 211-226). Leige, Belgium: University of Leige Press.

Silverman, S. (2017). Attitude research in physical education: A review. Journal of Teaching in Physical Education, 36, 303-312.

Silverman, S., Keating, X.D., \& Phillips, S.R. (2008). A lasting impression: A pedagogical perspective on youth fitness testing. Measurement in Physical Education and Exercise Science, 12, 146-166.

Silverman, S., Kulinna, P., \& Crull, G. (1995). Skill-related task structures, explicitness, and accountability: Relationships with achievement. Research Quarterly for Exercise and Sport, 66, 32-40.

Silverman, S., \& Subramaniam, P.R. (1999). Student attitude toward physical education and physical activity: A review of measurement issues and outcomes. Journal of Teaching in Physical Education, 19, 97-125.

Society of Health and Physical Educators. (2012). Instructional framework for fitness education in physical education [Guidance document]. Reston, VA: Author.

Society of Health and Physical Educators. (2014). National standards \& grade-level outcomes for K-12 physical education. Champaign, IL: Human Kinetics.

Solmon, M. A. (2003). Student issues in physical education classes: Attitudes, cognition, and motivation. In S. J. Silverman, \& C. D. Ennis (Eds.), Student learning in physical education: Applying research to enhance instruction (pp. 147-163). Champaign, IL: Human Kinetics.

Stevens, J. P. (2009). Applied multivariate statistics for the social sciences $\left(5^{\text {th }}\right.$ ed.). London, UK: Routledge Academic. 
Stewart Stanec, A. D. (2009). The Theory of Planned Behavior: Predicting teachers' intentions and behavior during fitness testing. Journal of Teaching in Physical Education, 28, 255-271.

Stodden, D., Sacko, R., \& Nesbitt, D. (2017). A Review of the Promotion of Fitness Measures and Health Outcomes in Youth. American Journal of Lifestyle Medicine, 11, 232-242.

Subramaniam, P.R., \& Mercier, K. (2017). Attitudes matter in physical education. International Journal of Physical Education, 54(4), 22-30.

Subramaniam, P. R., \& Silverman, S. (2000). Validation of scores from an instrument assessing student attitude toward physical education. Measurement in Physical Education and Exercise Science, 4, 29-43.

Subramaniam, P. R., \& Silverman, S. (2007). Middle school students' attitudes toward physical education. Teaching and Teacher Education, 23, 602-611.

Sweeting, T., \& Rink, J. (1999). Effects of direct instruction and environmentally designed instruction on the process and product characteristics of a fundamental skill. Journal of Teaching in Physical Education, 18, 216-233.

Troiano R.P., Berrigan D., Dodd K.W., Masse L.C., Tilert T., \& McDowell, M. (2008). Physical activity in the United States measured by accelerometer. Medicine and Science in Sports and Exercise, 40, 181-188.

Trost, S.G., Saunders, R., \& Ward, D.S. (2002). Determinants of physical activity in middle school children. American Journal of Health Promotion, 26, 95-102.

U.S. Department of Health and Human Services (2008). 2008 Physical activity guidelines for Americans. Centers for Disease Control and Prevention.

U.S. Department of Health and Human Services (2012). Adolescent and school health: Childhood obesity. Centers for Disease Control and Prevention.

Verjovsky, J., \& Waldegg, G. (2005). Analyzing beliefs and practices of a Mexican high school biology teacher. Journal of Research in Science Teaching, 42, 465-491.

Wayne, A. J., \& Young, P. (2003). Teacher characteristics and student achievement gains: A review. Review of Educational Research, 73, 89-122.

Welk, G.J., Maduro, P.F., Laurson, K.R., \& Brown, D.D. (2011). Field evaluation of the new FITNESSGRAM® criterion-referenced standards. American Journal of Preventive Medicine, 41, S131-S142. 
Wenglinsky, H. (2002). The link between teacher classroom practices and student academic performance. Educational Evaluation and Policy Analysis, 10, 12.

Wenglinsky, H. (2003). Using large-scale research to gauge the impact of instructional practices on student reading comprehension. Educational Policy Analysis Archives, 11, 9.

Whitehead, J. (1989). Creating a Living Educational Theory from Questions of the Kind, 'How Do I improve My Practice?' Cambridge Journal of Education, 19, 41-52.

Whitehead, J.R., Pemberton, C.L. \& Corbin, C.B. (1990). Perspectives on the physical fitness testing of children: The case for a realistic educational approach. Pediatric Exercise Science, 2, 111-23.

Wiersma, L.D., \& Sherman, C.P. (2008). The responsible use of youth fitness testing to enhance student motivation, enjoyment, and performance. Measurement in Physical Education and Exercise Science, 12, 167-183.

Windschitl, M., \& Sahl, K. (2002). Tracing teachers' use of technology in a laptop computer school: The interplay of teacher beliefs, social dynamics, and institutional culture. American Educational Research Journal, 39, 165-205.

Wittberg, R., Cottrell, L. A., Davis, C. L. \& Northrup, K. L. (2010). Aerobic fitness thresholds associated with fifth grade academic achievement. American Journal of Health Education, 41, 284-291.

Zanna, M.P., \& Rempel, J.K. (1988). Attitudes: A new look at an old concept. In D. BarTal \& A.W. Kruglanski (Eds.), The social psychology of knowledge (pp. 315334). Cambridge, England: Cambridge University Press.

Zhu, X., \& Chen, S. (2015). The impacts of adolescents' beliefs in performing a cardiorespiratory fitness test. International Journal of Sport and Exercise Psychology, 13, 182-192.

Zhu, X., Chen, S., \& Parrott, J. (2014). Adolescents' interest and performances in aerobic fitness testing. Journal of Teaching in Physical Education, 33, 53-67.

Zhu, W., Mahar, M. T., Welk, G. J., Going, S.B., \& Cureton, K. J. (2011). Approaches for development of criterion-referenced standards in health-related youth fitness tests. American Journal of Preventive Medicine, 41, S68-S76. 


\title{
APPENDICES
}

\section{Appendix A}

\section{Demographic Questionnaire}

Are you a certified physical education teacher?
O Yes
O No

What grade(s) do you teach? (select all that apply)
$\square$ 6th
口 7th
口 8th
$\square$ Other (please specify)

Do you co-teach any of your classes?
O Yes
O No

How many classes do you co-teach? What grade(s)?

\author{
How many? \\ What Grade(s)?
}

What is your age? (please enter a number, for example, "23")

What is your gender?
O Male
Female
Other (please specify) 
Please specify your ethnicity. (select all that apply)

$\square$ White
$\square$ Black or African American
$\square$ Asian
$\square$ American Indian or Alaska Native
$\square$ Native Hawaiian or Pacific Islander
$\square$ Hispanic
$\square$ Mixed Race
$\square$ Other (please specify)

How many years have you been teaching? (please enter a number, for example, "7")

What is the highest degree you have earned?
O Bachelor's (B.A., B.S.)
O Master's (M.A., M.S., M.Ed.)
Doctorate (Ph.D., Ed.D., Psy.D., M.D.)

How many times (average) do students attend your class each week? (please enter a number, for example, "3")

How many minutes (average) is each class you teach? (please enter a number, for example, "45")

How many students (average) are in each class you teach? (please enter a number, for example, "20") 
Have you had previous experience with fitness tests?

Y Yes

When have you had experience with fitness tests? (select all that apply)

口 $\mathrm{K}-12$ student

$\square$ Undergraduate student

- Graduate student

$\square$ Continuing professional development

$\square$ Other, please describe

Have you attended Continuing Professional Development (CPD) on fitness testing?

$\begin{array}{ll}\bigcirc & \text { Yes } \\ \mathrm{O} & \text { No }\end{array}$

How many total hours of Continuing Professional Development (CPD) on fitness testing have you had? (estimate clock hours)

Do you have your students to self-assess their own fitness test performance at any point during the school year?

O Yes

O No 
How many times do your students self-assess their fitness test performance each year? (please enter a number, for example, "7")

Do you use fitness tests results to:

\begin{tabular}{|c|c|c|}
\hline Determine students' fitness & Yes & No \\
levels? & O & \\
Track students' physical & & \\
progressions? & & \\
Help students' self-assess & & \\
their physical abilities? & 0 & 0 \\
\hline
\end{tabular}




\section{Appendix B}

Physical Education Teacher Attitudes toward Fitness Tests Scale (PETATFTS)

1. I feel time flies when my students are taking fitness tests. (A-I)

2. The results of my students' fitness tests are useless. (C-U)

3. My students' fitness test results help me effectively evaluate my students' health related fitness. (C-U)

4. I dislike using the results of my students' fitness tests to modify my physical activity/fitness instruction. (A-U)

5. I enjoy implementing fitness tests in my classes. (A-I)

6. The results of fitness tests inaccurately reflect what students learned from my physical activity/fitness instruction. (C-U)

7. I ignore the results of my students' fitness tests. (A-U)

8. The results of fitness tests help my students understand their health-related fitness. (C-U)

9. I feel it is fun when my students take fitness tests. (A-I)

10. I care about my students' fitness test results. (A-U)

11. I enjoy watching my students taking fitness tests. (A-I) 
12. The results of fitness tests motivate my students to participate in physical activity on a regular basis. (C-U)

13. I dislike spending my teaching time on implementing fitness tests. (A-I)

14. The results of fitness tests can be used to assess the effects of my physical activity/fitness instruction. (C-U)

15. My students seem to ignore their fitness tests results. (A-U) 


\section{Appendix C \\ Pilot Study - Teacher Invitation Letter}

Dear Physical Education Teacher,

I hope this note finds you well!

I am writing to request your assistance and feedback on a 10-15 minute online pilot survey for my dissertation research study looking into urban middle school physical education teachers' attitudes toward fitness testing and how these attitudes relate to their students' performance on fitness tests.

Your participation in this study is voluntary and anonymous. At the end of the survey you will be asked to provide feedback on the survey's clarity, functionality and ease of use.

You can accept the invitation by clicking on the link provided below:

Follow this link to the Survey:

Take the Survey

Or copy and paste the URL below into your internet browser: https://tccolumbia.qualtrics.com/SE?Q_SS=bdptyCDrTzgI2EJ_0ByayNpdTrV7rA9\&Q_ $\mathrm{CHL}=\mathrm{email}$

Or, if you do not wish to receive further emails concerning the survey: Opt Out

This research study is supervised by Dr. Stephen Silverman, professor in the Department of Biobehavioral Sciences at Teachers College, Columbia University. If you have any questions about the study, please contact me (rnf2108@ tc.columbia.edu or 347-3271661) or Professor Silverman (ss298@ tc.columbia.edu or 212-678-3324). I appreciate you taking the time to consider participating in the pilot study.

I appreciate your help with this pilot study!

Sincerely,

Ray N. Fredrick III

Doctoral Student

Department of Biobehavioral Sciences

Teachers College, Columbia University| ray.fredrick@tc.columbia.edu 


\section{Appendix D}

\section{Participant's Rights and Consent}

\section{PARTICIPANT'S RIGHTS}

- I have read the Research Description above and understand that my participation in this study is completely voluntary.

$>$ I may refuse to participate or withdraw from participation at any time without jeopardy to future medical care, employment, student status or other entitlements.

$>$ The researcher may withdraw me from the research at his/her professional discretion.

$>$ If, during the course of the study, significant new information that has been developed becomes available which may relate to my willingness to continue to participate, the investigator will provide this information to me.

$>$ Any information derived from the research project that personally identifies me will not be voluntarily released or disclosed without my separate consent, except as specifically required by law.

$>$ If at any time I have any questions regarding the research or my participation, I can contact the investigator, Ray N. Fredrick III (rnf2108@tc.columbia.edu), who will answer my questions.

$>$ If at any time I have comments or concerns regarding the conduct of the research or questions about my rights as a research subject, I should contact the Teachers College, Columbia University Institutional Review Board /IRB. The phone number for the IRB is (212) 678-4105. Or, I can write to the IRB at Teachers College, Columbia University, 525 W. 120th Street, New York, NY, 10027, Box 151.

$>$ For my personal records, I should print a copy of the Research Description and this Participant's Rights document. 


\section{PARTICIPANT'S CONSENT}

By checking the box below and clicking "Next", I agree to participate in this study.

YES, I have read and understand the above, and I agree to participate in this study.

NO, I have read and understand the above, and I do not agree to participate in this study. 


\section{Appendix E \\ Administrator Invitation Letter}

Dear Administrator,

My name is Ray N. Fredrick III and I am a doctoral student in the Curriculum \& Teaching in Physical Education program at Teachers College, Columbia University. I am the primary investigator for a dissertation research study designed to learn more about urban middle school physical education teachers' attitudes toward physical fitness testing and how these attitudes relate to student performance on fitness tests. I would like to request the assistance of your district and teachers in carrying out this study and your permission for the district to participate.

As part of the research, urban middle school physical education teachers will complete an online survey (15-20 minutes). If teachers agree to participate in the survey, then they will also be invited to participate in the second part of the study, which will involve correlating their attitude scores with their students' fitness tests scores. Teachers will have the option and are welcome to participate in the survey, but decline participation in the second part of the study. All responses will be kept confidential and used exclusively by the investigator for research purposes. Participation in the study is voluntary and anonymous. The results from the study may help to inform you and your district about important issues in education and I, therefore, will send you a summary of the results upon completion of the study.

This research study is supervised by Dr. Stephen Silverman, professor in the Department of Biobehavioral Sciences at Teachers College, Columbia University. If you have any questions about the study, please contact me (ray.fredrick@tc.columbia.edu or 347-327-1661) or Professor Silverman (ss928@ tc.columbia.edu or 212-678-3324).

Thank you for taking the time to consider participating in the study. 
Sincerely,

Ray N. Fredrick III

Doctoral Student | Department of Biobehavioral Sciences

Teachers College, Columbia University | ray.fredrick@tc.columbia.edu 


\section{Appendix F \\ Administrator Rights and Consent}

Dear Administrator,

Thank you for agreeing to allow your district to be a part of this research study. This research could not be done without your help! Participation in the study is still voluntary and anonymous. As part of a requirement for the Teachers College (TC) Institutional Review Board (IRB) I am required to obtain your signature, which shows that your district is agreeing to participate.

I am the primary investigator for this research study. This research study is supervised by Dr. Stephen Silverman, professor in the Department of Biobehavioral Sciences at Teachers College, Columbia University. If you have any questions about the study, please contact me (ray.fredrick@tc.columbia.edu or 347-327-1661) or Professor Silverman (212-678-3324).

Please sign both copies and return one to me via email as soon as possible. The other copy is for your records.

I appreciate you taking the time to participate in the study. Again, the results from the study may help to inform you and your district about important issues in education and I, therefore, will send you a summary of the results upon completion of the study.

Sincerely,

Ray N. Fredrick III

Doctoral Candidate

Department of Biobehavioral Sciences

Teachers College, Columbia University

ray.fredrick@tc.columbia.edu

By signing here I agree that district will

participate in the study: Urban Middle School Physical Education Teachers' Attitudes toward Physical Fitness Testing and the Relationship with Students' Performance on Fitness Tests, pending the approval of the Teachers College Institutional Review Board.

Administrator Signature: Date:

Print

Name: 
Appendix G

Student Demographic and FITNESSGRAM® Data Request Sheet

\section{Description}

Link to teacher Unique ID

Grade Level

Date of Birth

Age

Gender

Ethnicity

SES

Diagnostic or Final FITNESSGRAM®

Student height in inches

Student weight in pounds

Body Mass Index

The \# of laps on the PACER test

The number of minutes for the mile run

The number of seconds for the mile run

The number of curlups

The \# of inches for the trunk lift test

The \# of pushups

The \# of inches for the sit and reach

Yes or No for BMI HFZ

Yes or NO for cardio HFZ

Yes or NO for curlups HFZ

Yes or No for Trunk Lift HFZ

Yes or No for pushups HFZ

Yes or No for sit and reach HFZ 